\author{
RESEARCH ARTICLE \\ 10.1029/2019JB018219 \\ Key Points: \\ - Models of magma flow rates are \\ presented for six post-eruptive \\ magmatic intrusions under El \\ Hierro volcano from June 2012 to \\ March 2014 \\ - Initial magma flow rates of $\sim 300$ \\ $\mathrm{m}^{3} / \mathrm{s}$ decaying exponentially with \\ time are inferred using GPS and \\ InSAR, and a Bayesian inversion \\ approach \\ - A deep magma body likely fed the \\ inferred sill-like intrusions with a \\ conduit to a common feeding point \\ under the center of the island
}

Supporting Information:

- Supporting Information S1

Correspondence to:

M. A. Benito-Saz,

mabenito@fomento.es

Citation:

Benito-Saz, M. A., Sigmundsson, F., Charco, M., Hooper, A., \& Parks, M. (2019). Magma flow rates and temporal evolution of the 2012-2014 posteruptive intrusions at el hierro, canary islands. Journal of Geophysical Research: Solid Earth, 124, 12,576-12,592.

https://doi.org/10.1029/2019JB018219

Received 16 JUN 2019

Accepted 28 OCT 2019

Accepted article online 7 NOV 2019

Published online 13 DEC 2019

(C)2019. American Geophysical Union. All Rights Reserved.

\section{Magma Flow Rates and Temporal Evolution of the 2012-2014 Post-Eruptive Intrusions at El Hierro, Canary Islands}

\author{
Maria Angeles Benito-Saz ${ }^{1}$ (D), Freysteinn Sigmundsson ${ }^{2}$ (D), Maria Charco $^{3}$ iD, \\ Andrew Hooper ${ }^{4}$ iD, and Michelle Parks 5 iD \\ ${ }^{1}$ Instituto Geográfico Nacional, Madrid, Spain, ${ }^{2}$ Nordic Volcanological Center, Institute of Earth Sciences University of \\ Iceland, Reykjavik, Iceland, ${ }^{3}$ Instituto de Geociencias, CSIC-UCM Madrid, Spain, ${ }^{4}$ COMET, School of Earth and \\ Environment, University of Leeds Leeds, UK, ${ }^{5}$ Icelandic Meteorological Office, Iceland
}

\begin{abstract}
The 2011-2014 volcanic activity at El Hierro (Canary Islands) was characterized by a 5-month long submarine eruption as well as a series of magmatic intrusions occurring between 5 months and 2 years after the eruption, as revealed by seismic swarms and ground deformation. We study the temporal evolution of the six post-eruptive magmatic intrusions, using Global Navigation Satellite System and Interferometric Synthetic Aperture Radar observations complemented with relocated earthquakes. Magma volumes and magma supply rates are determined from inversion of the geodetic data using a Bayesian approach. The intrusions last between $\sim 3$ and 20 days and are inferred to be sill-like, thin compared with their lateral extent and emplaced in the $\sim 13-16 \mathrm{~km}$ depth range. Initial magma flow rates of $\sim 300 \mathrm{~m}^{3} / \mathrm{s} \mathrm{decay}$ exponentially with time. The two largest intrusions occurred in June-July 2012 and March-April 2013. During each of these events, magma migrated laterally, and $>120 \times 10^{6} \mathrm{~m}^{3}$ of magma was intruded beneath the island. The shortest events, $<1$ week-long, intruded $\sim\left(24\right.$ hyphen;44) $\times 10^{6} \mathrm{~m}^{3}$ of magma beneath the volcano. We suggest that all intrusions originated from an overpressure in a deep magma body located beneath the center of El Hierro. The crust/mantle boundary and the previous intrusion that fed the 2011-2012 submarine eruption may have discouraged the ascent of the post-eruptive intrusions to the surface and forced them to migrate laterally away from the island as sill-like sources.
\end{abstract}

\section{Introduction}

Magmatic intrusions within the crust typically produce seismicity and ground deformation around them (e.g., Segall, 2013). In some volcanic systems, magma migrates laterally for kilometers before finding its way to the surface. For example, magma intruded beneath the summit of the Miyakejima volcano (Izu Islands, Japan) on 26 June 2000 and migrated for over $30 \mathrm{~km}$ with a velocity of $\sim 4.4 \mathrm{~km}$ /day before a caldera collapse started 2 weeks later, accompanied by several summit phreatic and phreatomagmatic eruptions during the following 3 months (e.g., Toda et al., 2002). However, lateral migration of magma through the crust does not always culminate in an eruption. For example, Lamongan volcano (Java island, Indonesia) showed up to $12 \mathrm{~cm}$ of line-of-sight (LOS) displacement, mapped by interferometric analysis of synthetic aperture radar satellite images (InSAR) between September and December 2007, suggesting arrival of new magma beneath the volcano. Several seismic swarms occurred below the volcano in 1985, 1988, 2005, and 2012, but no eruption has yet taken place (e.g., Chaussard \& Amelung, 2012).

The lateral flow of magma in the crust has been modeled in detail for a few magmatic intrusive episodes. At Eyjafjallajökull volcano (Iceland), an earthquake swarm was detected in 1999 and modeled using the surface deformation recorded. More than $20 \mathrm{~cm}$ of LOS displacement on the southern flanks of the volcano was inferred, with a migration of the center of deformation through time (Pedersen \& Sigmundsson, 2006). On August 2014, a dike intrusion began in the Bárðarbunga volcanic system (Iceland), growing laterally for $>45 \mathrm{~km}$ over $\sim 14$ days, revealed by propagating seismicity, ground deformation, and graben formation, before an eruption occurred (e.g., Sigmundsson et al., 2015). At the Red Sea Rift in Afar (Ethiopia), more than a dozen diking events occurred from 2005 to 2009 in a major rifting episode (e.g., Ebinger et al., 2010). However, few studies track the movement and evolution of horizontal (sill) intrusions over significant distances (e.g., Wauthier et al., 2016), and the forces and geophysical conditions that make sill intrusions 
propagate laterally or ascend to the surface are still being studied by in-field observations, laboratory experiments, and numerical models (e.g., Gudmundsson, 2011; Kavanagh, 2018; Rivalta et al., 2015).

The 2011-2014 volcanic activity at El Hierro island (Canary Islands, Spain) revealed the occurrence of deep multiple magmatic intrusions. Each episode was characterized by intense seismicity and significant ground deformation. Furthermore, some of the intrusions showed clear lateral migration of magma. The first intrusion, which began in mid-July 2011, propagated laterally for over $15 \mathrm{~km}$ before leading to a submarine eruption on 10 October 2011. The subsequent intrusions did not reach the surface, although producing significant surface displacements (Benito-Saz et al., 2017; Domínguez Cerdeña et al., 2018). Intrusions in June-July 2012 and March-April 2013 showed lateral migration of seismicity away from the center of the island for $>15 \mathrm{~km}$.

Previous deformation modeling studies have been undertaken at El Hierro during the 2012-2014 post-eruptive activity (Benito-Saz et al., 2017). Here, we complement that study by modeling the temporal and spatial evolution of the intrusions to improve understanding of the processes related to magma supply, storage, and dynamics. We gain insight into magmatic activity during these intrusions by a joint analysis of relocated earthquakes and high-quality GNSS and InSAR geodetic observations (Benito-Saz et al., 2017; Domínguez Cerdeña et al., 2018). Magma volumes and magma flow rates during each intrusive event are determined from inversion of the geodetic data, contributing to a better understanding of the magmatic activity beneath this intraplate volcano.

\section{El Hierro Island}

The Canary Islands, $\sim 100 \mathrm{~km}$ west of the northern coast of Africa, are an active intraplate volcanic region located $>1700 \mathrm{~km}$ from the Mid-Atlantic Ridge. The archipelago is formed by a $\sim 500-\mathrm{km}$-long chain of seven main volcanic islands in a compressive stress regime, with direction of maximum horizontal stresses oriented NNW-SSE at the easternmost islands and NW-SE at the westernmost ones, as El Hierro (Geyer et al., 2016). El Hierro is the emergent summit of a shield volcano with $~ 95 \%$ of its volume below sea level (Figure 1).

At El Hierro, periods of growth resulting from volcanic activity have alternated with phases of quiescence, erosion, and lateral flank collapses (e.g., Carracedo et al., 2001). The catalog of eruptions, although still incomplete, documents 25 eruptions in the last $158 \mathrm{ka}$, with only 5 eruptions in the last $5 \mathrm{ka}$. Most of the eruptions have been characterized as monogenetic mafic eruptions of 0-2 Volcanic Explosivity Index (VEI) (Becerril et al., 2014). The submarine volcanic cone created in 2011-2012 was named Tagoro, referencing a ceremonial meeting place of the first human settlers that arrived on El Hierro 2,500 years ago.

At El Hierro, the basaltic oceanic crust/mantle discontinuity is located at 11-15 km depth (Martí et al., 2017). A magma accumulation zone, characterized by high density and high seismic velocity, is located to at least 10-12 km depth under the central part of the island. This area may correspond to a series of intrusions, already solidified, as inferred from inversion of gravity observations and seismic tomography (e.g., Martí et al., 2017; Sainz-Maza et al., 2017).

\section{El Hierro 2011-2014 Magmatic Intrusions and Eruptive Activity}

Major activity in El Hierro began in mid-July 2011 with the onset of an intense earthquake swarm under the center of the island. For 2 months, seismicity migrated $\sim 10 \mathrm{~km}$ from north to south of the island at depths of 9-11 km (Figures 1, 2). From 27 September onward, magmatic activity changed, with an increase in the surface deformation rate and deeper seismic hypocenters, up to $16 \mathrm{~km}$ depth. The deepening of seismicity with time has been interpreted to reflect the increase in depth of a strained crustal volume due to additional magma emplacement (López et al., 2017), tracking an inclined structure (Domínguez Cerdeña et al., 2018; Martí et al., 2017). On 3 October, the focal mechanism of earthquakes changed from thrust to strike-slip, probably due to a change in the stress field, with one of the nodal planes aligned with the direction of maximum horizontal compressive stress in the island (López et al., 2017). A $\mathrm{M}_{\mathrm{w}} 4$ earthquake on 8 October, the largest event during the entire pre-eruptive seismic swarm, has been interpreted to mark the beginning of the magma upward migration toward the surface (e.g., López et al., 2017). A swarm of shallow low 
a)

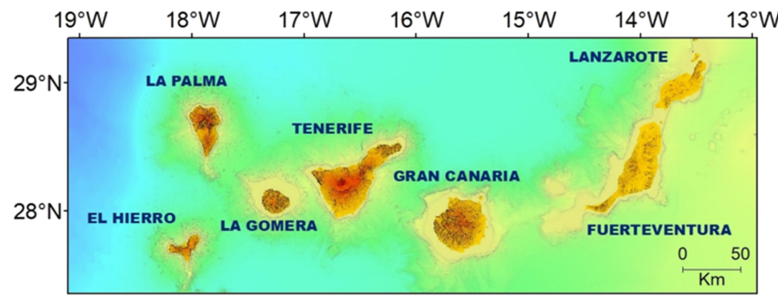

b)

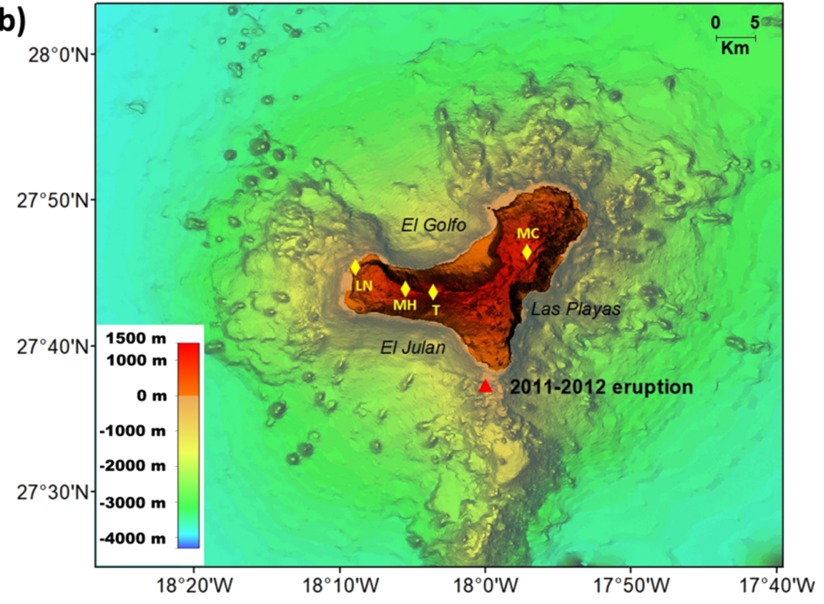

c)
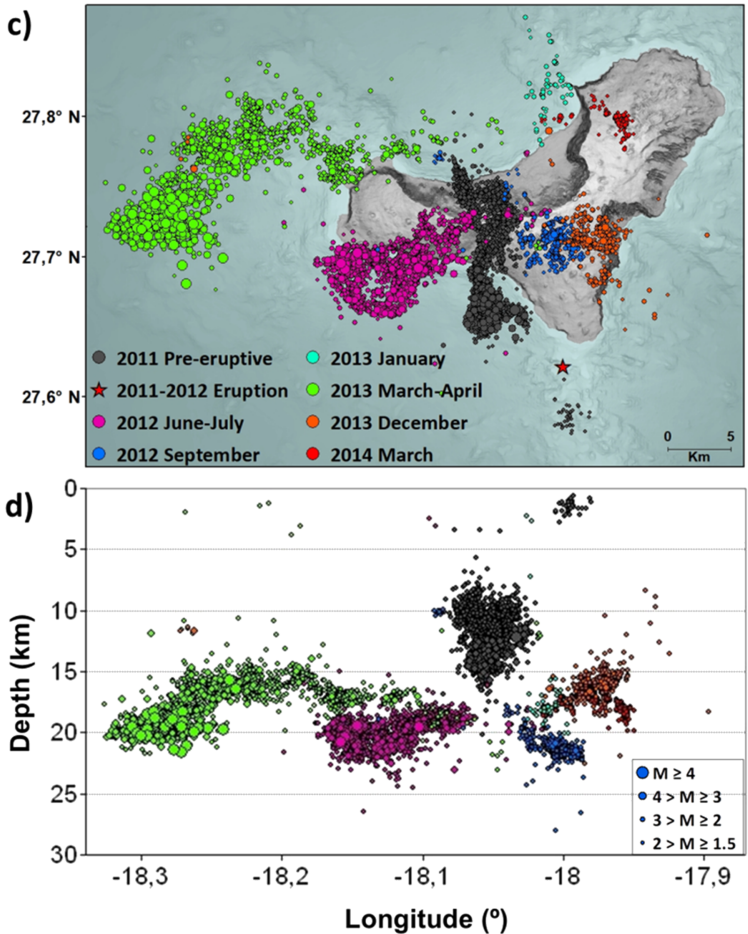

Figure 1. (a) Map of the Canary Islands with the names of the islands indicated. (b) Topography and bathymetry of El Hierro island. Three ridges extending to the northeast, south, and west from the center of the island are clearly seen both onshore and offshore. Main massive landslides are indicated: El Golfo ( $87-39 \mathrm{ka})$, Las Playas ( 176-145 ka), and El Julan (>200 ka) collapses. Centers of the last eruptions on the island are shown with yellow diamonds: MH = Montaña de los Humilladeros $(5.10 \pm 0.04 \mathrm{ka}), \mathrm{T}=$ Tanganasoga $(4.00 \pm 0.07 \mathrm{ka}), \mathrm{MC}=$ Montaña Chamuscada $(2.50 \pm 0.07 \mathrm{ka})$, and Lomo Negro eruptions $(<2.1 \mathrm{ka})(\mathrm{e} . \mathrm{g}$., Carracedo et al., 2001; Villasante-Marcos \& Pavón-Carrasco, 2014). The 2011-2012 Tagoro volcano is marked with a red triangle. (c) Epicenters and (d) depth versus longitude of relocated earthquakes recorded at El Hierro for each of the 2011-2014 intrusions (Domínguez Cerdeña et al., 2014, 2018). Earthquakes are shown in a different color for each intrusion. Magnitude of earthquakes is proportional to the size of the dots.

magnitude earthquakes was registered 23 min after this event, continuing until the onset of the submarine eruption on 10 October (Figures 1, 2).

During the entire pre-eruptive period, seismicity migrated $\sim 15 \mathrm{~km}$. The only GNSS station installed on the island before the beginning of the activity, FRON (see Figure 4 for station location), registered $\sim 5 \mathrm{~cm}$ of inflation (e.g., Domínguez Cerdeña et al., 2018).

The submarine eruption (VEI 2) occurred $<2 \mathrm{~km}$ south of the island (e.g., Becerril et al., 2014), and explosive and effusive activity phases alternated during 4 months (e.g., Somoza et al., 2017). The eruption ended on 15 February 2012 (Sanchez-Pastor et al., 2018), and the volcanic cone, Tagoro, grew in multiple stages of growth and collapses from 375 to $89 \mathrm{~m}$ water depth, with a total eruptive volume of $\sim 400 \times 10^{6} \mathrm{~m}^{3}$ (Somoza et al., 2017).

Magmatic processes at El Hierro remained active for the following 2 years with the occurrence of, at least, six well-detected post-eruptive magmatic intrusions (e.g., Benito-Saz et al., 2017; Díaz-Moreno et al., 2015; Domínguez Cerdeña et al., 2018; Klügel et al., 2015). These intrusions were characterized by the nearly simultaneous beginning of seismicity and ground deformation (e.g., Lamolda et al., 2017). Seismic swarms occurred at depths between $\sim 15$ and $23 \mathrm{~km}$, and $>20 \mathrm{~cm}$ of cumulative surface uplift was recorded in the central and western part of the island (Benito-Saz et al., 2017) (Figures 1, 2).

During the two largest intrusions that occurred in June-July 2012 and March-April 2013, clear lateral migration of seismicity away from the center of the island was observed (Figure 3). During the June-July 2012 intrusion, seismicity moved at a velocity of $\sim 1.1 \mathrm{~km} /$ day during the first week to a distance of $\sim 14$ $\mathrm{km}$ from the center of the island. During the March-April 2013 event, seismicity moved at the same velocity but for a period of 2 weeks, to a distance of $\sim 28 \mathrm{~km}$ from the center of the island. 
a)

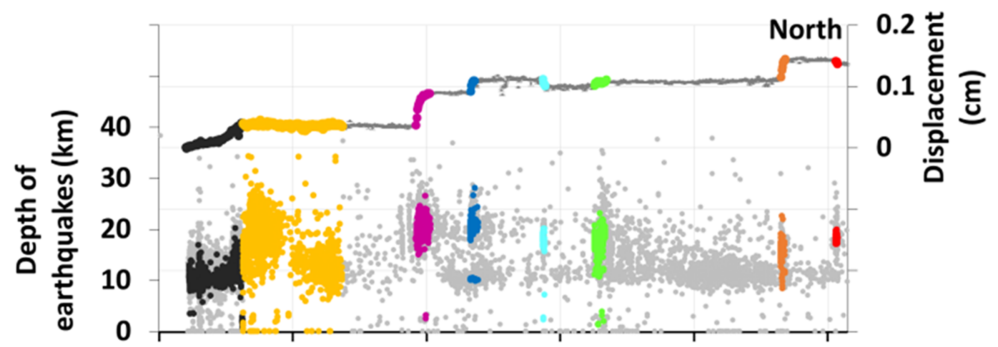

b)

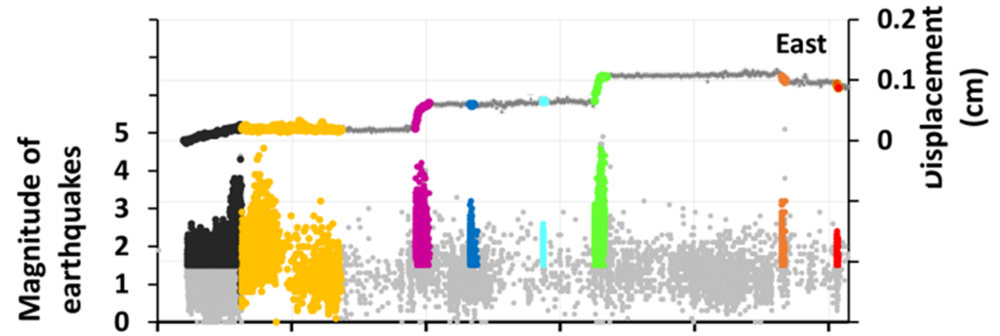

c)

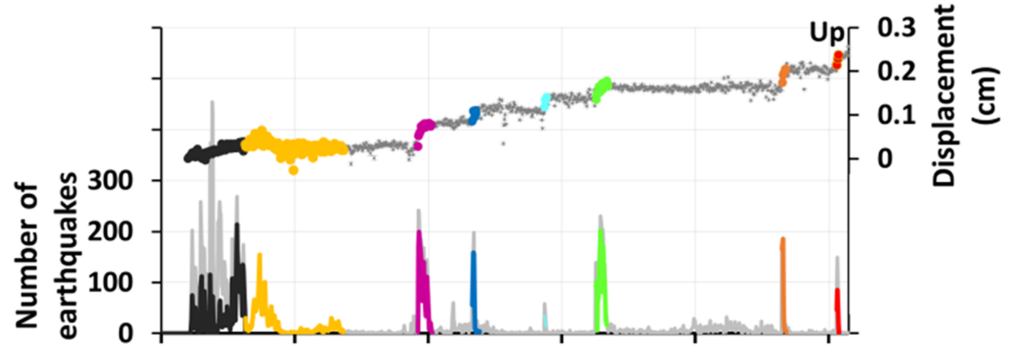

d)

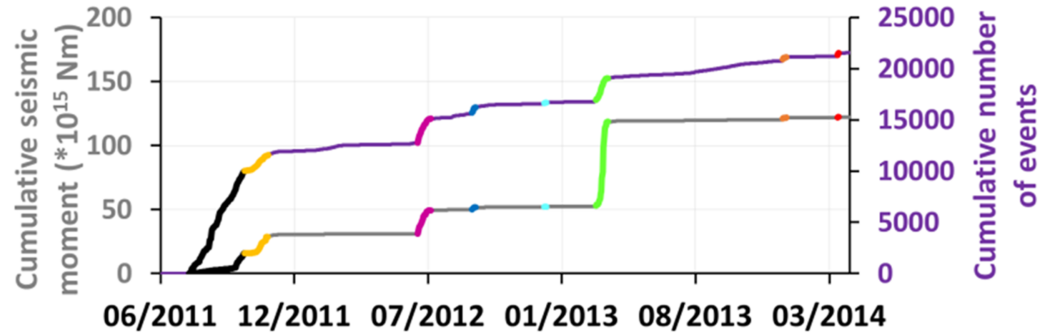

Figure 2. Temporal evolution of seismicity and GNSS data recorded at station FRON (see Figure 4 for station location) from June 2011 to March 2014 at El Hierro island. Left axes show (a) depth, (b) magnitude, and (c) number of daily earthquakes, and (d) cumulative seismic moment. Right axes show (a) northward, (b) eastward, and (c) vertical displacements, relative to the beginning of June 2011, and (d) cumulative number of earthquakes. Nonrelocated earthquakes from the Spanish National Geographic Institute catalog (www.ign.es) are represented in light grey. Relocated earthquakes (Domínguez Cerdeña et al., 2014, 2018) are represented in the same color used in Figure 1.

\section{Data and Methods}

\subsection{Earthquake Hypocenter Relocations}

High-precision relocations of earthquakes (Domínguez Cerdeña et al., 2018) were used to interpret the seismic activity during the 2012-2014 post-eruptive episodes. Over 4,700 earthquakes with $\mathrm{M}>1.5$ occurring between June 2012 and March 2014 at El Hierro were relocated using the double-difference method of the hypoDD algorithm and a four-layer velocity model of El Hierro (Dañobeitia, 1980) (Table S1). Due to the geometric form of the island, earthquakes occurring offshore show less well-constrained hypocenter positions, since both the velocity model and the absolute accuracy of hypocenters depends on the availability of observations from near-field stations. Seismic location relative uncertainties of 1-3 km were inferred 


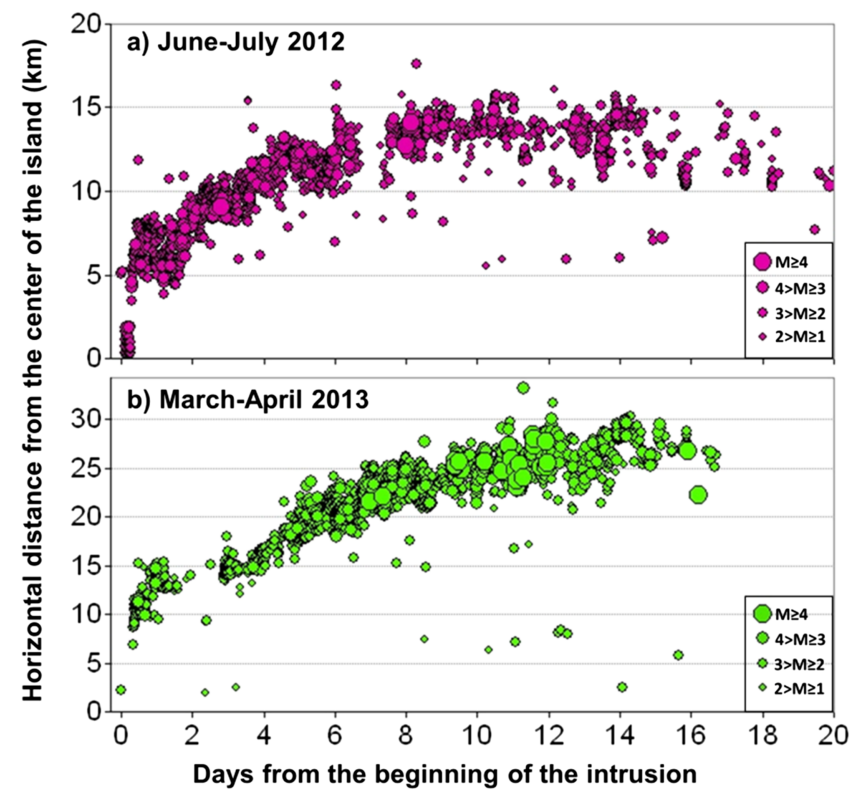

Figure 3. Spatiotemporal evolution of relocated earthquakes away from the center of the island during (a) June-July 2012 and (b) March-April 2013 intrusions. The vertical axis shows distance of epicenters from $18.020^{\circ} \mathrm{W}$ to $27.728^{\circ} \mathrm{N}$, considered to represent the center of the island. The horizontal axis shows time (in days) since the beginning of intrusions. Magnitude of earthquakes is proportional to the size of the dots. considering random deviations of up to $1 \mathrm{~km} / \mathrm{s}$ in velocity and $6 \mathrm{~km}$ in depth of each layer boundary of the velocity model (Domínguez Cerdeña et al., 2018).

\subsection{GNSS Processing}

Time series of horizontal and vertical displacements at ten continuous GNSS sites installed on the island from June 2012 and March 2014 were utilized throughout this study. The GNSS stations recorded signals from the Global Positioning System (GPS). GPS data (30-s sampling) were processed at the National Geographic Institute of Spain (IGN) using Bernese GNSS software v5.2. Data from a regional network of $>30$ GNSS stations located in the Canary Islands, Azores, Spain, and Africa were included in the processing. The ITRF2008 reference frame was used, implemented by minimum constraints to an International GNSS Service (IGS) core site group of five stations. The ocean-loading model FES2004, atmospheric tidal loading, the IGS absolute antenna phase center models for both satellite and ground-based station antennas, and the IGS precise satellite orbits were also used. Tropospheric path delays were estimated using the Global Mapping Function. As a result of the Bernese processing, geocentric coordinates were obtained daily for each station and transformed to north, east, and up daily time series. The plate movement was then removed according to NUVEL-1A model using the UNAVCO Plate Motion Calculator (https://www.unavco.org). Therefore, all GNSS surface displacements shown here are relative to stable African Plate (Figures 4, 7, 8, S1-S2, S21-S22, and S40) (Benito-Saz et al., 2017; Domínguez Cerdeña et al., 2018).

\subsection{InSAR Analysis}

We processed time series of interferograms from C-band satellite radar images acquired by the Canadian RADARSAT-2 (RDS-2) satellite and X-band radar images acquired by the Italian COSMO-SkyMed (CSK) satellites (Table S2) (Benito-Saz et al., 2017), using the StaMPS software (Hooper et al., 2012). A 5-m resolution digital elevation model obtained from LIDAR data at the IGN (www.ign.es) was used in the InSAR workflow for removal of topographic fringes. We employed both persistent scatterer and small baseline

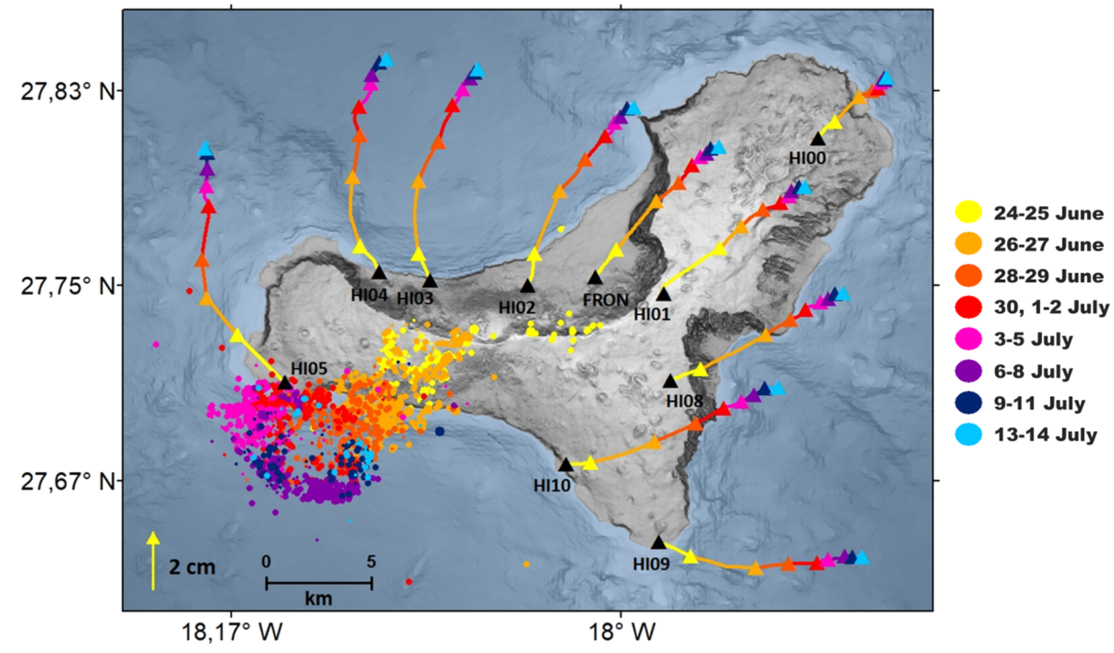

Figure 4. El Hierro June-July 2012 intrusion. Spatiotemporal evolution of relocated epicenters (dots) and horizontal ground displacement (triangles) recorded at the GNSS stations from 14 June to 14 July 2012, color coded by time. GNSS stations are located by black triangles and indicated by their name. 
approaches for time series generation. Although these methods are optimized for different models of ground scattering, they are complementary and by combining the results obtained by both approaches, the spatial sampling, the signal-to-noise ratio, and, therefore, the phase unwrapping accuracy are increased (Hooper et al., 2012). A linear phase-based method was used to remove the signal correlated with the topography using the TRAIN toolbox (Bekaert et al., 2015). Although the interferometric phase also reflects spatial variation of the tropospheric properties, turbulence, and other confounding effects (e.g., Lin et al., 2010), at El Hierro the linear correction method has been found to provide an improved RMSE reduction than other tropospheric correction techniques (Bekaert et al., 2015) (Figure S5). InSAR data (Tables S3 and S8 and Figures S3 and S23) and GNSS observations are compared in Supporting Information Figures S4 and S24.

\subsection{Deformation Modeling}

Cumulative daily deformation data were calculated based on the continuous GNSS time series, and InSAR data when available, and inverted using a Bayesian probabilistic inversion approach to infer the deformation sources (Bagnardi \& Hooper, 2018).

In the inversion process, we assumed GNSS displacements to be uncorrelated with LOS displacements. The weights of the different geodetic data sets were provided by the inverse of the error variance-covariance matrices. The variance-covariance matrix for the InSAR data was estimated by modeling experimental semivariograms in deformation-free regions assuming an exponential covariance function in the form cov = sill* $\mathrm{e}^{(-3 h / \text { range })}+$ nugget (Bagnardi \& Hooper, 2018). In the equation, $h$ is the distance between the measurement points, and the sill, nugget, and range values are obtained from the semivariograms. The nugget indicates the level of spatially independent noise present, and the sill is the maximum value of the semivariance as the range tends to infinity. The range is the distance at which correlation of the noise between points drops below $5 \%$. We calculated a sill of $2 \times 10^{-4} \mathrm{~m}^{2}$, a nugget of $1 \times 10^{-5} \mathrm{~m}^{2}$, and a range of $6 \mathrm{~km}$ for the RADARSAT-2 interferograms and a sill of $1.1 \times 10^{-4} \mathrm{~m}^{2}$, a nugget of $0.1 \times 10^{-5} \mathrm{~m}^{2}$, and a range of $11 \mathrm{~km}$ for CSK interferograms (Benito-Saz et al., 2017).

The variance-covariance matrix for the GNSS data was obtained from the GNSS uncertainties estimated during the Bernese processing at 95\% confidence level, with the off-diagonal elements set to zero assuming no covariance exists between station displacements nor the three components of displacements at each GNSS site. Mean GNSS variance-covariance values were almost an order of magnitude smaller than the InSAR variance-covariance values, and therefore, more weight was given to the GNSS data in the modeling.

Additional modeling carried out using only InSAR observations showed that the location of the sources was well constrained but not the volume. Only when inverting GNSS and InSAR data sets together were position and volume of the sources well determined. In addition, we also tried setting an additional factor to decrease the variance of the GNSS data to give the GNSS data points weight the corresponding InSAR subsampled points. However, in those cases, the source was located far from the island in an unrealistic position (Table S5 and Figure S11).

We calculated the daily temporal and spatial evolution of the volcanic sources responsible for the observed ground deformation using several different approaches, including analytical models of point pressure sources (Mogi, 1958) and horizontal penny-shaped cracks representing sill-like sources (Fialko et al., 2001). Source location and volume for the point pressure sources and source location, pressure, and radius for the penny-shaped cracks were considered free parameters in the inversion process. We initially also used the spherical source model (McTigue, 1987) considering the effect of topography using the method of Williams and Wadge (1998), but results were very similar as those from using point pressure center models. Therefore, the topography of the island was not considered for simplicity, and depths obtained here are referenced to a surface approximately equal to the average observation height, $\sim 450 \mathrm{~m}$.

We also tested a rectangular dislocation model representing an opening dike (Okada, 1992). However, due to the small area of the island, the limits of the dike did not converge to realistic values. Therefore, we modeled the magmatic intrusions as horizontal pressurized sill cracks of irregular shape and variable opening using a stress-driven mechanical boundary element method (BEM) (Hooper et al., 2011). We divided the potential source area into 121 horizontal square patches of $1.5 \mathrm{~km}$ length and width, assuming a traction-free interface. We first calculated the unitary stresses at every patch in the three principle directions (normal, along strike, and along dip) for unit displacement in each principle direction for each patch in turn, using the 
equations for rectangular dislocations of Okada (1992). Using the geometry, depth, and magma overpressure of the sill crack for each iteration, the spatial distribution of opening and slip on each selected element were then uniquely determined following the method of Hooper et al. (2011).

An elastic, homogeneous, isotropic half-space was assumed in all approaches, with Poisson's ratio of 0.25 and shear modulus of $40 \mathrm{GPa}$ (Watts, 1994). We calculated the weighted residual sum of squares (WRSS) divided by the degrees of freedom to evaluate the fitness of the model to the data.

Magma volume rates were evaluated and compared to models where magma flow rates, $Q$, decayed exponentially with time, $t$, in the form

$$
Q(t)=Q_{0} \exp ^{\left(\frac{-t}{\tau}\right)}
$$

with $Q_{0}$ being the initial magma flow rate and $\tau$ the relaxation time (Dvorak \& Okamura, 1987). The cumulative magma volume, $V$, at time $T$ is

$$
V(T)=\int_{t=0}^{T} Q(t)=Q_{0} \tau\left(1-\exp \left(\frac{-T}{\tau}\right)\right)
$$

\section{Results}

\subsection{June-July 2012 Intrusion}

Between 24 June and 14 July 2012, hundreds of volcano-tectonic earthquakes, mostly $\mathrm{M}<4$, were located at 18-24 km depths below the central and western part of the island. For the first 7 days, seismicity migrated southwestward away from the island for $\sim 15 \mathrm{~km}$ at a velocity of $\sim 1.1 \mathrm{~km} /$ day. After a half-day hiatus, and for the following 13 days, seismicity was mostly confined to the southernmost part of the seismic area. The number of earthquakes decreased, and the cumulative seismic moment increased gradually with time with punctuated increments on 3, 7, and 8 July. The GNSS data and CSK and RDS- 2 interferograms showed $>60 \mathrm{~mm}$ of horizontal displacements in an evolving radial pattern and $>40 \mathrm{~mm}$ of uplift at the central and western part of the island. The GNSS stations on the island recorded horizontal displacements higher than vertical displacements, except for the GNSS sites located nearest to the seismicity, HI10 and HI05. Those stations recorded the highest uplift of $95 \mathrm{~mm}$, which was higher than their horizontal displacements, being $>90 \mathrm{~mm}$ and $>75$ mm measured at HI10 and HI05, respectively. Approximately $80 \%$ of the surface uplift was recorded during the first 5 days at velocities of up to $15 \mathrm{~mm} /$ day, whereas $80 \%$ of the horizontal displacements were measured in the first 8 days, with velocities up to $9 \mathrm{~mm}$ /day (Figures 3, 4, 5, S1-S4).

The evolution of seismicity and surface deformation, with propagating seismicity and a clear change in direction of horizontal surface displacements, suggests a magmatic intrusion under the southwestern part of the island and offshore, evolving with time. Daily evolution of best-fit analytical models, assuming either (i) a point source of pressure or (ii) a horizontal penny-shaped geometry, indicates a source center located southeast of the seismicity and moving southwest with time for $>4 \mathrm{~km}$ (Figure 5 and Tables S4 and S6). Although seismicity shows an increase in the depth of the hypocenters as they moved away from the island (Díaz-Moreno et al., 2015; Domínguez Cerdeña et al., 2018), the geodetic data infer a source propagating laterally along a same depth. Point pressure sources are located at $\sim 11.7 \mathrm{~km}$ depth, whereas penny-shaped cracks with radius $\sim 5 \mathrm{~km}$ are at $\sim 15 \mathrm{~km}$ depth, closer to the seismic hypocenters. Trade-offs between model parameters do not account for the difference (Figures S6-S7, S12-S13, and S16). This difference in depth between both models may be due in part to the limited availability of observations from close-in GNSS stations, since most of the surface deformation field may be ocurring offshore. Optimal penny-shaped crack models predict a total intruded magma volume of $(167 \pm 65) \times 10^{6} \mathrm{~m}^{3}$ (95\% confidence interval). Residuals between surface observations and predictions from the maximum likelihood models are shown in Figures S8-S9 and S14-S15. Geodetic models obtained show WRSS $\leq 2$ when jointly inverting GNSS and InSAR data and mainly overestimate vertical displacements in the southwestern part of the island and underestimate horizontal displacements in the north coast.

We also employed a mechanical BEM to better characterize the geometry of the intrusion. Since the depth of the analytical models remains near constant throughout the duration of the intrusion (Tables S4 and S6), we defined the intrusion as a horizontal pressurized sill crack, dividing the possible area of intrusion into 121 
a)
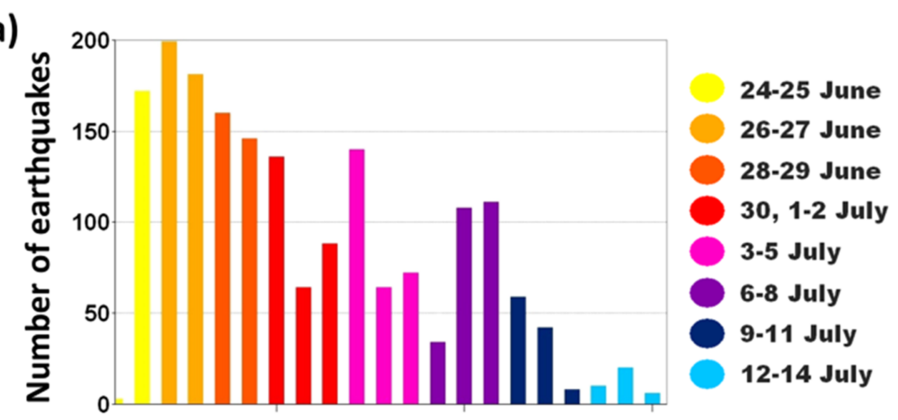

b)

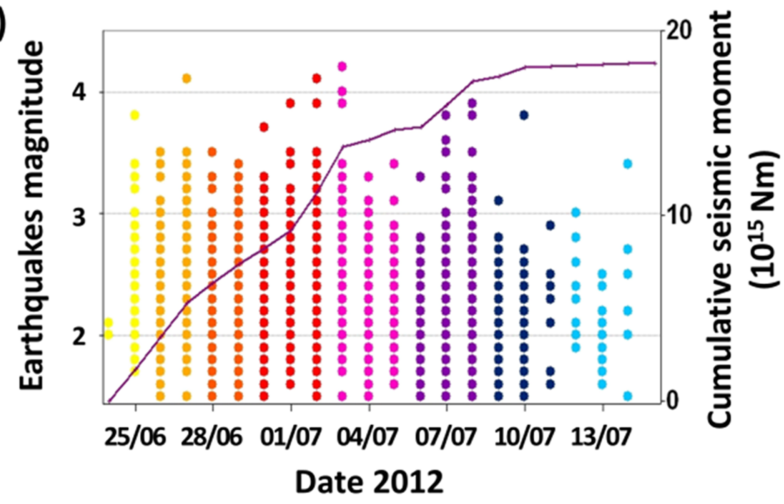

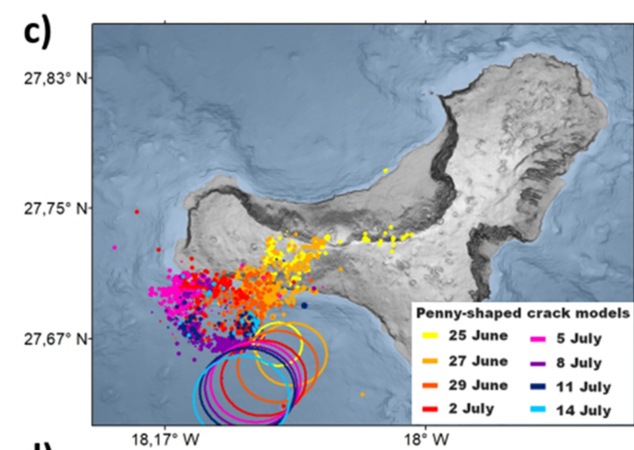

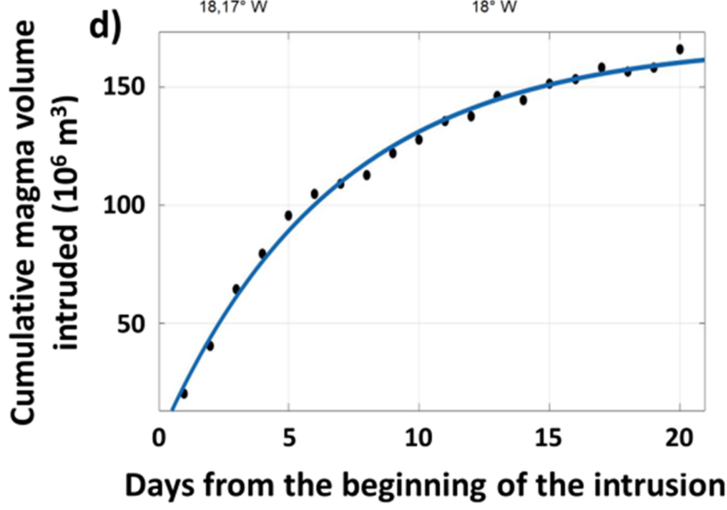

Figure 5. El Hierro June-July 2012 intrusion. Daily evolution from 24 June to 14 July 2012 of (a) number and (b) magnitude of relocated earthquakes (left axis) and cumulative seismic moment (right axis), color coded by time. (c) Spatiotemporal evolution of relocated epicenters (small dots) and surface projection of optimal penny-shaped crack models (circles) for the same time period, using the same color coded by time. (d) Cumulative magma volume intruded below the island considering the daily optimal penny-shaped crack models presented in (c). The injected cumulative magma volume is fitted to an exponential equation as in equation (2) with an inferred initial magma flow rate of $293 \pm 17 \mathrm{~m}^{3} / \mathrm{s}$ and a relaxation time of $7 \pm 1$ days $\left(95 \%\right.$ confidence bounds, $\left.\mathrm{R}^{2}=0.99\right)$.

patches of $1.5 \mathrm{~km}$ length and width. We first ran the model for the entire period of the intrusion considering the GNSS and InSAR data available. Results indicate an intrusion at $15.9 \pm 0.3 \mathrm{~km}$ depth. We then fixed the depth at $15.9 \mathrm{~km}$ and calculated the temporal evolution of the sill considering the cumulative surface deformation since the onset of the intrusion until the time of the modeling. Results predict a volcanic source increasing in area and migrating toward the southwest in a similar manner as the seismicity. The sill opening increases with time, with maximum openings of $0.6 \mathrm{~m}$ at the beginning of the intrusion to 2 $\mathrm{m}$ at the end of the event. Strike-slip and dip-slip predicted by the models are negligible $(<5 \mathrm{~mm})$. The total intruded magma volume according to this model is $(124 \pm 7) \times 10^{6} \mathrm{~m}^{3}$, with $80 \%$ of the volume intruded during the first 8 days (Figures 6 and S17-S20 and Table S7).

The cumulative magma volume inferred by these three geodetic models presents a decay that can be fitted to an exponential equation as in equation (2), with an inferred initial magma flow rate of $276-341 \mathrm{~m}^{3} / \mathrm{s}$, decaying with a relaxation time of 4-7 days (95\% confidence bounds) (Figures 5, 6 and S10).

\subsection{March-April 2013 Intrusion}

On 18 March 2013, a seismic swarm began under the northwestern part of the island at 13-22 km depth and continued for $\sim 18$ days. During the first two days, seismic hypocenters were located near the western part of the island. After a hiatus of 1 day, the daily number of earthquakes increased gradually, and epicenters (mostly $\mathrm{M}<3$ ) migrated northwest for $\sim 7 \mathrm{~km}$. From 25 March, earthquake patterns changed again, with the migration toward the southwest, covering a distance of $\sim 15 \mathrm{~km}$ in $\sim 7$ days. Although the number of earthquakes decreased gradually during this time, the rate of seismic moment increased $(21 \mathrm{M}>4$ earthquakes occurred). In total, seismicity migrated $\sim 25 \mathrm{~km}$ with a velocity of $\sim 1.1 \mathrm{~km} /$ day. Rapid vertical and eastward surface displacements occurred on the central and western parts of the island based on analysis of InSAR and GNSS data. Approximately $80 \%$ of the horizontal and vertical displacements recorded at the GNSS stations on the island occurred during the first week. The maximum surface displacement was 

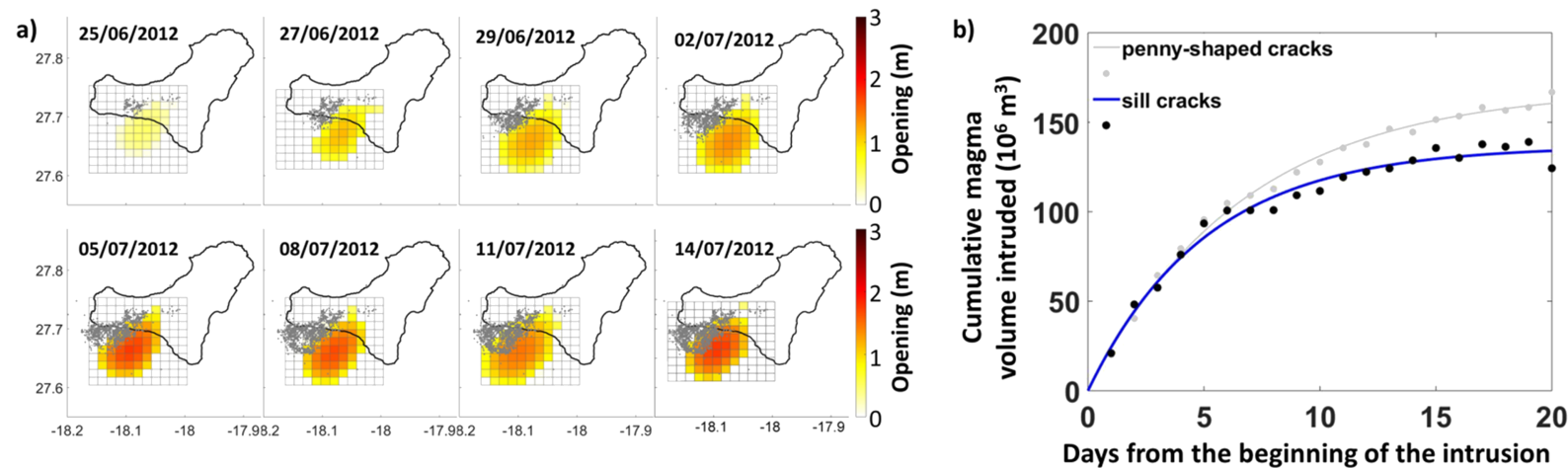

Figure 6. El Hierro June-July 2012 intrusion. (a) Spatiotemporal evolution of relocated epicenters (grey dots) and surface projection of mean opening for the sill crack patches. Depth of the sill crack model is set to $15.9 \mathrm{~km}$. (b) Cumulative magma volume intruded below the island considering the daily optimal sill crack models presented in (a). The injected cumulative magma volume is fitted to an exponential equation as in equation (2) with an inferred initial magma flow rate of $311 \pm 30 \mathrm{~m}^{3} / \mathrm{s}$ and a relaxation time of $5 \pm 1$ days ( $95 \%$ confidence bounds, $\left.\mathrm{R}^{2}=0.98\right)$. The inferred cumulative magma volume intruded beneath the island considering the penny-shaped crack models (Figure $5 \mathrm{~d}$ ) has been overlaid for comparison.

recorded at GNSS station HI05, the westernmost site on the island, which recorded $>9 \mathrm{~cm}$ of eastward displacement and almost $12 \mathrm{~cm}$ of surface uplift during the entire event with velocities up to $13 \mathrm{~mm} /$ day. The rest of the GNSS stations recorded horizontal displacements higher than vertical displacements. GNSS station HI04, for example, located at the northwestern part of the island, recorded $7 \mathrm{~cm}$ of vertical displacement and $8 \mathrm{~cm}$ of horizontal displacement (94\% of the horizontal displacement corresponded to eastward component) (Figures 7 and S21-S24).

Ground deformation modeling indicates a volcanic source center moving westward with time and decreasing in depth during the first week. Best-fit point pressure models predict a source that evolves from 20 to $11 \mathrm{~km}$ depth during the first week, with a total intruded volume of $(125 \pm 15) \times 10^{6} \mathrm{~m}^{3}$ (Table S9 and Figures S25-S29). Optimal penny-shaped cracks, with $\sim 9 \mathrm{~km}$ radius, decrease in depth progressively from $\sim 27$ to $22 \mathrm{~km}$ during the first week, remaining at $\sim 21 \mathrm{~km}$ for the rest of the event. However, a much larger intruded volume, of $(489 \pm 203) \times 10^{6} \mathrm{~m}^{3}$, is predicted by this model (Table S10 and Figures S30-S34). The distance of the main intrusion area to the center of the island, $\sim 20 \mathrm{~km}$, increases the uncertainties of the source parameters, and penny-shaped crack models may be overestimating the volume of the intrusion. Sill crack models obtained employing the BEM reveal also the migration of the intrusion to shallower depths during the first week of the event, from 25 to $15 \mathrm{~km}$ depth, with openings up to $1.4 \mathrm{~m}$. Strike-slip and dip-slip vectors are negligible $(<4 \mathrm{~mm})$. The decrease in the depth of the source and its westward migration is also in agreement with hypocentral estimations using the hypoDD method performed by Díaz-Moreno et al. (2015). A total intruded volume of $(120 \pm 9) \times 10^{6} \mathrm{~m}^{3}$ is predicted by this model with $\sim 80 \%$ of the volume intruded during the first week. Calculation of the magma volume suggests an initial magma flow rate of $299 \pm 45 \mathrm{~m}^{3} / \mathrm{s}$ with a relaxation time of $5 \pm 1$ days (95\% confidence bounds) (Figures 7 and S35-S39 and Table S11).

\subsection{Other Post-Eruptive Intrusions}

Four other shorter magmatic intrusions, <1 week long, occurred beneath El Hierro between 2012 and 2014. These intrusions were also characterized by intense seismic activity and high rates of surface displacements (Figures 8 and S40-S41). Analytical models show sources increasing in volumes with time (Figures S42-S43 and Tables S12-S23).

From 14 to 19 September 2012, seismicity (M < 3.2) occurred at 19-24 km depth, below the central part of the island. Horizontal GNSS displacements were, in general, higher than vertical displacements, except for the sites located nearest to the seismic epicenters. GNSS stations HI09 and HI10 recorded $\sim 40 \mathrm{~mm}$ of surface uplift and almost $11 \mathrm{~mm}$ of horizontal displacements. Elastic analytical models indicate a volcanic source located $\sim 3.5 \mathrm{~km}$ south from the seismicity. Optimal point pressure centers are located at $\sim 12 \mathrm{~km}$ depth, while penny-shaped cracks with radius $\sim 3 \mathrm{~km}$ are at $\sim 16 \mathrm{~km}$ depth, closer to the seismic hypocenters. Results of sill cracks obtained using the BEM put the intrusion at $\sim 16 \mathrm{~km}$ depth with opening of up to $1.3 \mathrm{~m}$. These 


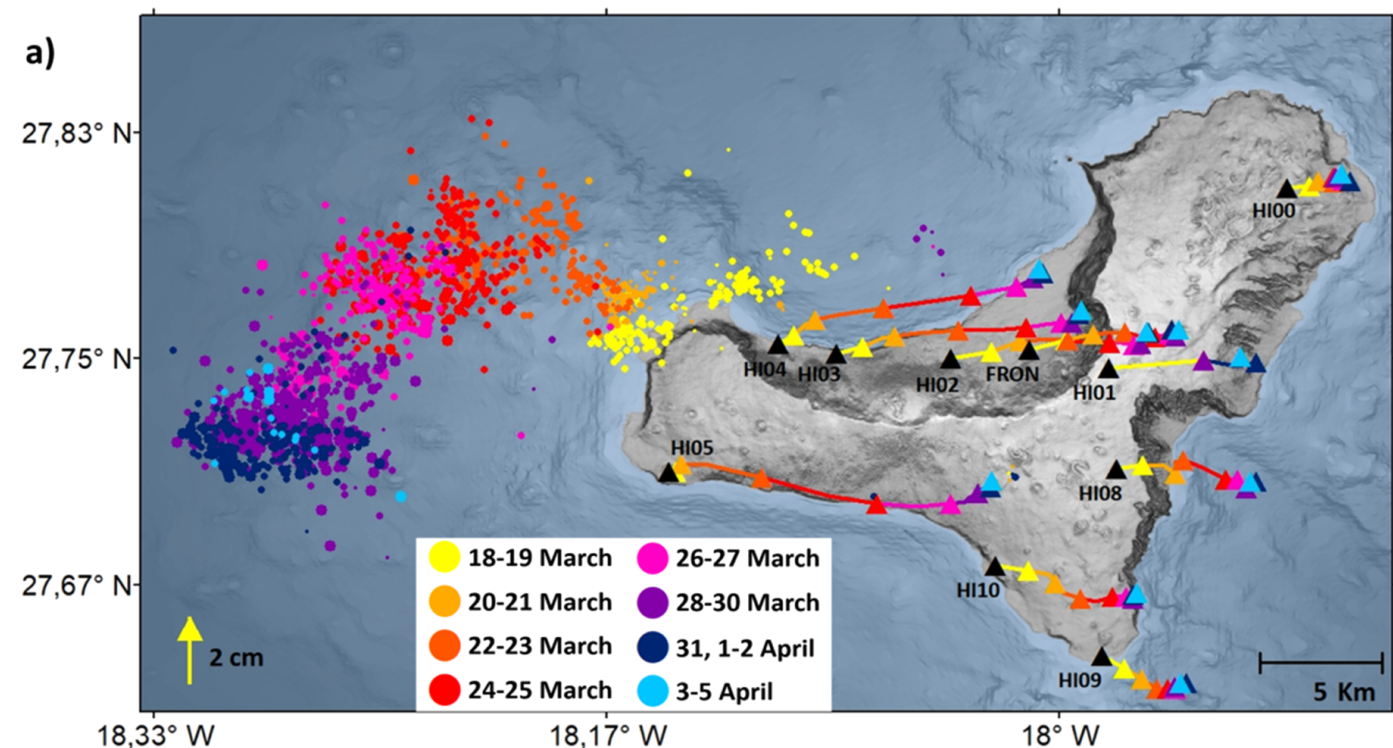

b)

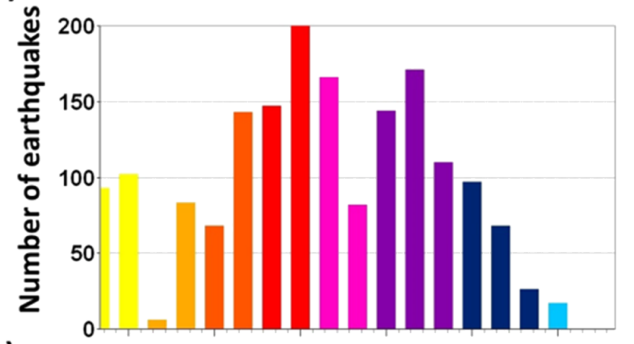

c)

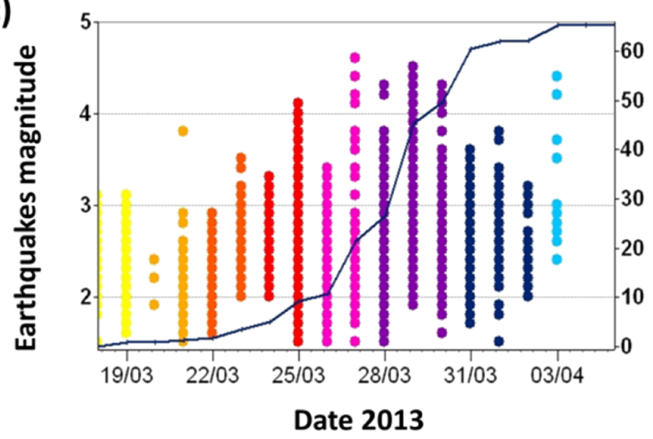

d)
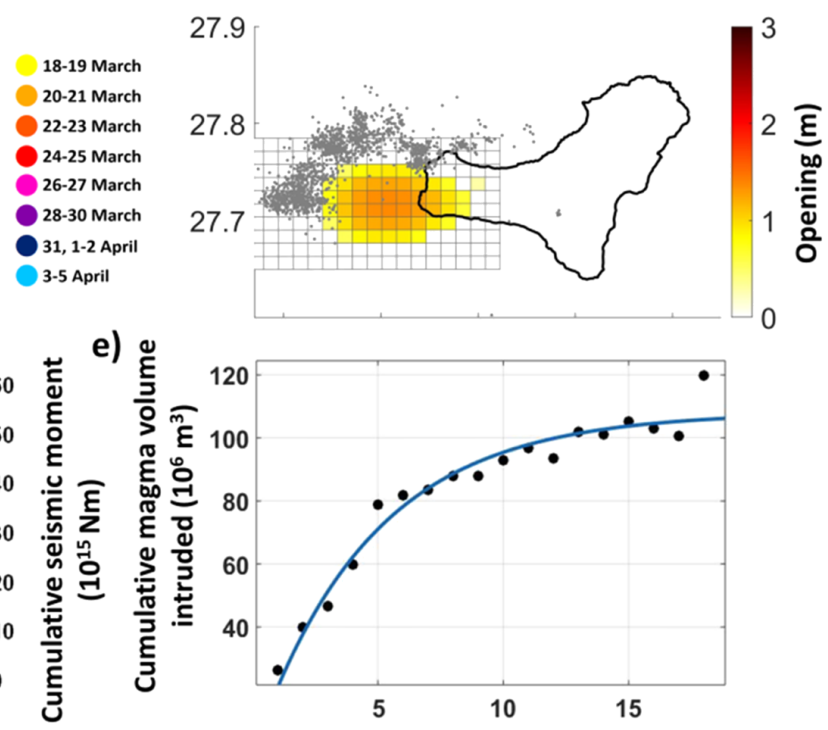

Days from the beginning of the intrusion

Figure 7. El Hierro 2013 March-April intrusion. (a) Spatiotemporal evolution of relocated epicenters (dots) and horizontal ground displacement (triangles) recorded at the GNSS stations from 18 March to 5 April 2013, color coded by time. GNSS stations are located by black triangles and indicated by their name. Daily evolution of (b) number and (c) magnitude of relocated earthquakes (left axis) and cumulative seismic moment (right axis) for the same time period.

(d) Relocated epicenters (grey dots) and surface projection of mean opening of the sill crack patches inferred for the time period 18 March to 5 April 2013.

(e) Cumulative magma volume intruded below the island considering the daily optimal sill crack models. The injected magma volume rate is fitted to an exponential equation as in equation (2) with an inferred initial magma flow rate of $299 \pm 45 \mathrm{~m}^{3} / \mathrm{s}$ and a relaxation time of $5 \pm 1$ days $\left(95 \%\right.$ confidence bounds, $\mathrm{R}^{2}=0.96$ )

geodetic models infer a total injected magma volume of $\sim 29 \times 10^{6} \mathrm{~m}^{3}$, with an initial magma flow rate of $\sim 283$ $\mathrm{m}^{3} / \mathrm{s}$ and relaxation time of $\sim 1$ day.

Approximately 3 months later, from $\sim 31$ December 2012 to 3 January 2013, a seismic swarm $(\mathrm{M}<2.6)$ occurred beneath the central-northern part of the island at depths of $16-20 \mathrm{~km}$. During the first day, seismicity migrated north for $\sim 4 \mathrm{~km}$. The GNSS station FRON, closer to the seismicity, recorded the maximum uplift, $\sim 38 \mathrm{~mm}$. Geodetic source models show a volcanic source moving $\sim 1 \mathrm{~km}$ north and increasing in volume up to $\sim 28 \times 10^{6} \mathrm{~m}^{3}$. Penny-shaped and sill crack models locate the source at $\sim 15 \mathrm{~km}$ depth, with 
September 2012

a)

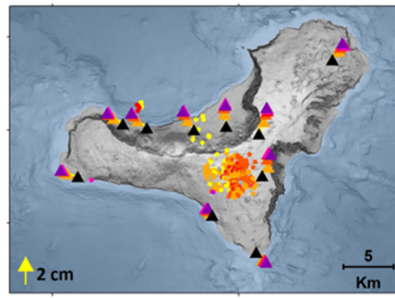

b) 4

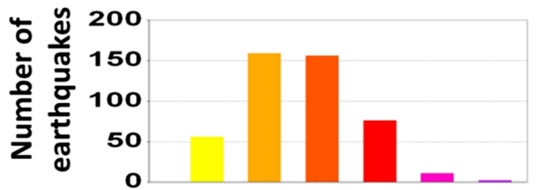

c)

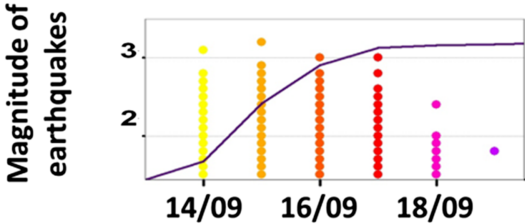

d)

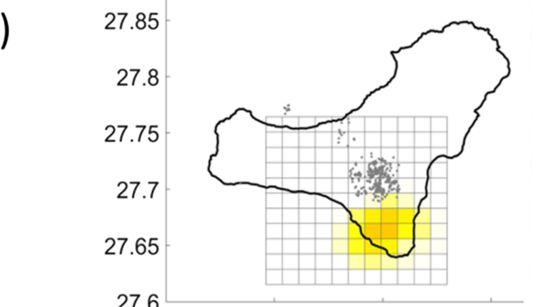

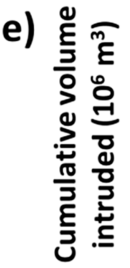

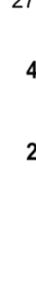

January 2013
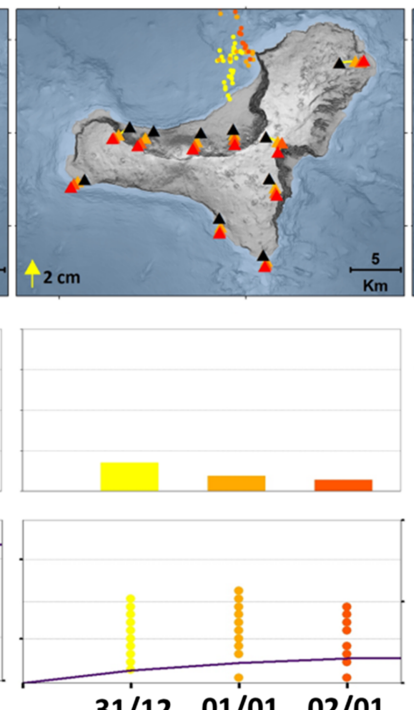

$31 / 12 \quad 01 / 01 \quad 02 / 01$
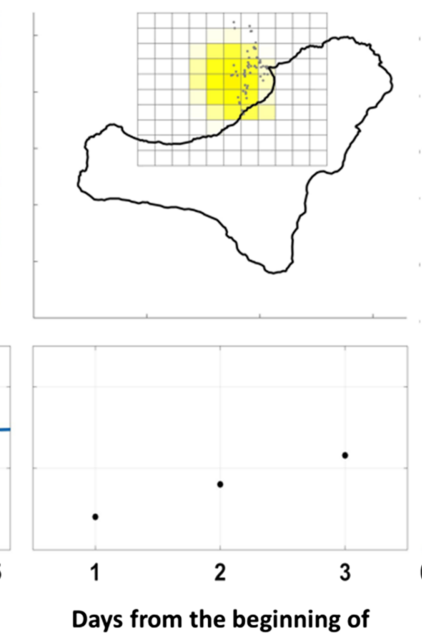

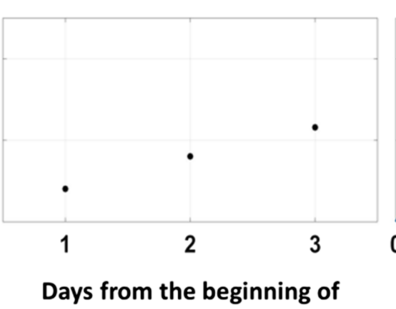

the intrusion
December 2013
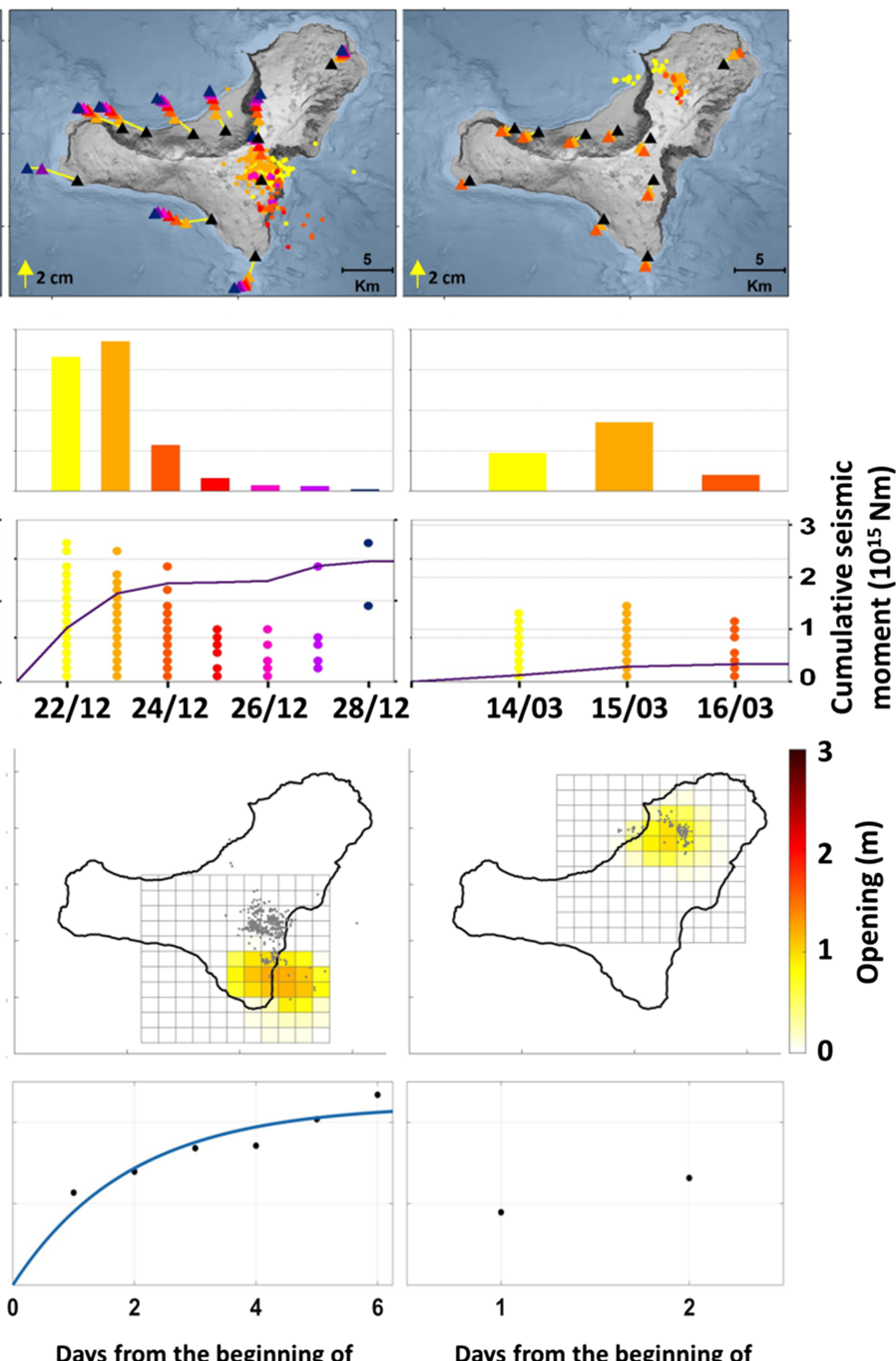

the intrusion
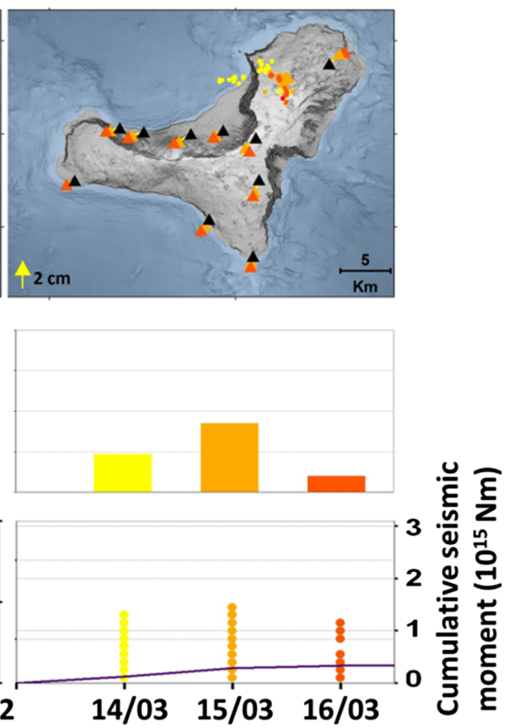

March 2014

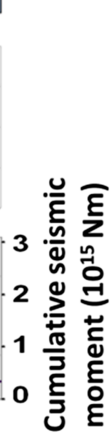

Figure 8. El Hierro September 2012, January 2013, December 2013, and March 2014 intrusions. (a) Spatiotemporal evolution of relocated epicenters (dots) and horizontal ground displacement (triangles) recorded at the GNSS stations during each of the intrusions, color coded by time. Daily evolution of (b) number and (c) magnitude of relocated earthquakes (left axis) and cumulative seismic moment (right axis) for the same intrusions. (d) Surface projection of relocated earthquakes (grey dots) and mean opening for the sill crack patches. (e) Cumulative magma volume intruded below the island considering the daily optimal sill crack models presented in (d). The injected magma volume rate is fitted to an exponential equation as in equation (2) for the September 2012 and December 2013 intrusions. The inferred initial magma flow rate for the September 2012 intrusion is $249 \pm 110 \mathrm{~m}^{3} / \mathrm{s}$ with a relaxation time of $1.4 \pm 0.8$ days ( $95 \%$ confidence bounds, $\left.\mathrm{R}^{2}=0.93\right)$. The inferred initial magma flow rate for the December 2013 intrusion is $267 \pm 149 \mathrm{~m}^{3} / \mathrm{s}$ with a relaxation time of $1.9 \pm 1.5$ days $(95 \%$ confidence bounds, $\left.\mathrm{R}^{2}=0.83\right)$.

increasing opening up to $1 \mathrm{~m}$. The evolution of the magma flow rate cannot be calculated due to the short duration of this intrusion.

On 22 December 2013, an intrusion occurred for 6 days with seismicity $(\mathrm{M}<3.2)$ located at $13-19 \mathrm{~km}$ depth below the central-eastern part of the island. High vertical displacements were recorded at the southern part of the island. At GNSS station HI08, located closest to the seismicity, $>80 \mathrm{~mm}$ of uplift and $>40 \mathrm{~mm}$ of horizontal displacement was recorded. While point pressure source models predict a geodetic source at $\sim 10 \mathrm{~km}$ depth, crack models locate the volcanic source at $\sim 13 \mathrm{~km}$ depth, with increasing opening up to $1.3 \mathrm{~m}$. All models infer a volcanic source that increases its volume up to $\sim 43 \times 10^{6} \mathrm{~m}^{3}$. An inferred initial magma flow rate of $\sim 269 \mathrm{~m}^{3} / \mathrm{s}$ decayed exponentially with a relaxation time of $\sim 2$ days. 


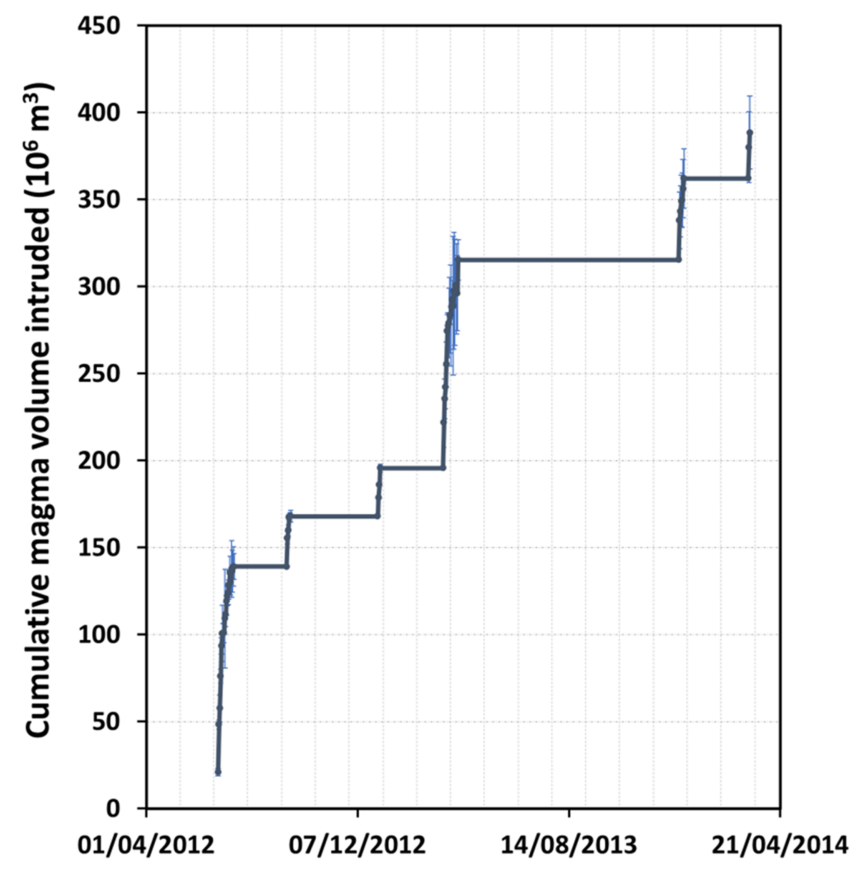

Figure 9. Magma volume intruded beneath El Hierro island from 2012 to 2014 according to the sill crack models. Error bars show 95\% confidence bounds.
The last intrusion of the episode occurred on March 2014. From $~ 14$ to 16 March, a seismic swarm $(M<2.4)$ was located in the northern part of the island at $17-20 \mathrm{~km}$ depth. Most of the surface deformation occurred on the eastern part of the island. GNSS station HI00 recorded $>35 \mathrm{~mm}$ of uplift and almost $15 \mathrm{~mm}$ of horizontal displacement. Best-fit point pressure sources are located at $\sim 12 \mathrm{~km}$ depth, while crack models are placed at $\sim 15 \mathrm{~km}$ depth, with opening up to $1.2 \mathrm{~m}$. These models predict a magma volume of $\sim 24 \times 10^{6} \mathrm{~m}^{3}$ emplaced beneath the island. Due to the short duration of this intrusion, there is too little data to calculate the evolution of the magma flow rate.

According to the sill crack models, $\sim 388 \times 10^{6} \mathrm{~m}^{3}$ of magma was intruded beneath the island from June 2012 to March 2014 (Figure 9). This volume corresponds to $\sim 0.01 \%$ of the total volume of the island, estimated at $\sim 3,200 \mathrm{~km}^{3}$ from terrain and bathymetry digital elevation models, or $\sim 0.3 \%$ of the subaerial volume of the island, $158 \mathrm{~km}^{3}$. This accumulation of magma produced $>10 \mathrm{~cm}$ of horizontal ground deformation in the island and $>20 \mathrm{~cm}$ of uplift in the central and western part, as revealed by GNSS and InSAR data sets.

\section{Discussion}

Seismicity and ground deformation between 2012 and 2014 reveal the emplacement of at least six well-defined magmatic intrusions, at depths of 13-24 km beneath El Hierro island.

\subsection{Deformation Modeling on a Small Island}

Modeling deep geodetic sources on a small island is an intrinsically difficult process. The restricted spatial area of observations limits the accuracy of the models and may bias the results. The geodetic data covers only a small part of the total deformed area since part of the surface deformation field is offshore. At Santorini volcano, for example, an intrusion occurred north of Nea Kameni island, beneath the water-filled caldera, where no observational data were available directly above the magmatic source but only on the surrounding islands (e.g., Hooft et al., 2019; Parks et al., 2015). In such instances, the real geometry of the intrusions is difficult to determine, given also the measurement errors in the GNSS and InSAR data and considering the fact that differences of $<30 \%$ in the ratio between maximum horizontal and vertical displacements can fit different geometries (Fialko et al., 2001).

The complete surface deformation field with an accuracy of millimeters is needed to obtain accurate geodetic models. However, separating surface deformation from tropospheric delays in InSAR interferometric signals remains one of the major challenges for the InSAR technique. At El Hierro, the main contribution to the InSAR tropospheric signal results from the topography correlated signal and the turbulence, increased by the high topography of the island in combination with the surrounding ocean. The effect of long wavelength spatial variation at El Hierro is limited due to the small extent of the island. A good network of GNSS sites around the island helps to constrain the temporal and spatial evolution of the location and volume of the magmatic sources.

In this work, we have employed several analytical models (Fialko et al., 2001; Mogi, 1958) and rectangular dislocation patches (Okada, 1992) using a BEM (Hooper et al., 2011) with a Bayesian inversion approach (Bagnardi \& Hooper, 2018) to infer the geodetic sources responsible for the observed ground deformation at El Hierro. Results reveal that simple geometry models using point source of pressure fit the ground deformation slightly better from the mathematical point of view (slightly lower WRSS values) than the other models. Point pressure sources (Mogi, 1958) are often employed to model simple spherical type magma bodies beneath volcanoes. Despite their simplistic geometry, they often fit deformation patterns reasonably well when modeling deep geodetic sources, such as that proposed beneath Hekla volcano (Iceland), where an inflating spherical source was inferred at 14-20 km depth between 1993 and 2008, prior and after the 2000 eruption (Ofeigsson et al., 2011). At El Hierro, we consider sill models more realistic than point 
source models, considering the temporal and spatial evolution of the intrusions. The point pressure source models and penny-shaped cracks (Fialko et al., 2001) indicate similar X,Y source locations for the intrusions; however these are located at different depths, with point pressure sources $\sim 3-4 \mathrm{~km}$ shallower than pennyshaped cracks. We find trade-offs between model parameters, for example, the source depth and the injected magma volume, such that the same surface deformation can be due to a deeper source with a larger magma volume or a shallower source with smaller volume. However, the joint inversion of multiple GNSS and InSAR observations reduces these trade-offs at El Hierro, and the difference in depth between the models cannot be accounted by these trade-offs. This discrepancy in depth has also been observed at other volcanoes showing deep inflating sources. As the ratio of radius to depth of the sill decreases, the difference in depth of the best-fitting sources increases. For example, point pressure sources were inferred to be between 5 and 8 $\mathrm{km}$ shallower than penny-shaped cracks for inflating sources at $\sim 13-25 \mathrm{~km}$ depth at Uturuncu volcano (Bolivia) between 1992 and 2000 and at Hualca Hualca volcano (Peru) from 1992 to 1997 (Pritchard \& Simons, 2004).

In general, horizontal intrusions can be well distinguished from spherical sources considering their faster decay of surface displacements in the far field (e.g., Fialko et al., 2001). However, the decreasing amplitude of the surface displacements in the far field also implies a decrease in the signal-to-noise ratio, and in the case of El Hierro, the limited area of the geodetic network restricts the results. In addition, the use of elastic homogeneous half-space models may bias the results toward spherical source geometries if the host rocks exhibit inelastic and/or anisotropic mechanical properties (e.g., Fialko et al., 2001). A BEM allows modeling the volcanic sources as a series of continuous patches and determining the distribution of opening and slip in space on each patch. Sill crack models inferred at El Hierro using this approach suggest sources of several $\mathrm{km}^{2}$ area with vertical openings of $\sim 1-2 \mathrm{~m}$ along the intrusions. The opening and area of the intrusions, together with the lateral movement of the sources, suggest sill-like intrusions, which are thin compared to their lateral extent.

The inferred geodetic sources at El Hierro are located shallower and slightly to the south of the seismicity area. However, due to the almost simultaneous beginning of seismicity and surface deformation, we suggest that both data sets reflect the same process, the emplacement of intrusions at depth, and not the occurrence of different processes at different levels. The reported difference in location may result from systematic errors in the inversions due to the limited spatial coverage of observed crustal deformation and seismic stations, constrained by the small size of the El Hierro island compared to the large area offshore. This can have a strong influence on the outcome of the inversion procedure. Depth estimates also depend on the assumption about the crustal structure. A horizontal homogeneous four-layered velocity model from 1980 (Dañobeitia, 1980) was used in the location of the seismicity. In contrast, a homogenous, elastic, isotropic half-space was used when inverting the geodetic data. However, El Hierro's crust shows lateral and vertical mechanical heterogeneities (e.g., Martí et al., 2017; Sainz-Maza et al., 2017). Thus, additional uncertainties will arise in the modeling related to this. In addition, seismic swarms may not represent the entire area of the intrusions. For example, during the 2014 Bárðarbunga dike intrusion, seismicity was focused at the lower edge of the dike (e.g., Parks et al., 2017; Sigmundsson et al., 2015), and during the 1999 intrusion at Eyjafjallajökull volcano, seismicity indicated the site of the upflow feeder channel for the intrusion, at its southern end (Pedersen \& Sigmundsson, 2006). The use of more GNSS and seismic stations, combined with a large number of SAR images at this small island, will reduce uncertainties, and more complex models constrained by seismic velocities, gravity observations, and fault plane seismic solutions may therefore help to better resolve the characteristics and dynamics of intrusive events in future studies.

\subsection{El Hierro Magmatic Intrusions}

According to the geodetic models, $>120 \times 10^{6} \mathrm{~m}^{3}$ of magma was intruded beneath El Hierro during the two largest events in June-July 2012 and March-April 2013. The shortest intrusions, $<1$ week long, intruded (24-44) $\times 10^{6} \mathrm{~m}^{3}$ of magma at the lower crust. In total, $388 \times 10^{6} \mathrm{~m}^{3}$ of magma is inferred to have been intruded beneath the volcano from June 2012 to March 2014. This magma volume is comparable to the volume of pyroclastic material emitted during the 2011-2012 submarine eruption, estimated at $400 \times 10^{6}$ $\mathrm{m}^{3}$ by oceanographic cruises (Somoza et al., 2017). Comparable intrusive volumes have also been found at other volcanoes. At Kilauea volcano, for example, magma supply rates of (80-280) $\times 10^{6} \mathrm{~m}^{3} / \mathrm{yr}$ were estimated for the period 2001 to 2012 (Anderson \& Poland, 2016). At Eyjafjallajökull volcano (Iceland), two 
intrusions occurred below the volcano in 1994 and 1999 with inferred magma volumes of $\sim(17-31) \times 10^{6} \mathrm{~m}^{3}$ (Pedersen \& Sigmundsson, 2006). Ten years later, a $\sim(49-71) \times 10^{6} \mathrm{~m}^{3}$ magmatic intrusion grew over a period of 3 months before an eruption occurred on 2010 (Sigmundsson et al., 2010).

The post-eruptive intrusions at El Hierro showed magma flow rates of $\sim 300 \mathrm{~m}^{3} / \mathrm{s}$ decaying exponentially with time. This exponential decay in the magma supply rate has also been observed at other volcanoes, as for example, the Three Sisters volcanic center from 2001 to 2006 (Dzurisin et al., 2009). At El Hierro, the initial flow rates and corresponding overpressures were not sufficient to enable the propagation of a magma conduit to the surface. In contrast, the intrusions were stacked at $\sim 13-16 \mathrm{~km}$ depth, and only when the magma supply lasted for several days was the intruded magma able to migrate laterally.

We suggest that intrusions at El Hierro were supplied with magma from an over-pressurized magma body in the mantle connected with a conduit to a feeding point to the intrusive complex beneath the central part of the island. The beginning of seismicity during the pre-eruptive and the post-eruptive intrusions occurred in all cases beneath the center of the island, where the highest part of the island is located, indicative of a longterm magma upflow path. Utilizing forward calculation for a spherical point source of pressure at the center of the island and evaluating the minimum depth of this deep magma body required to produce less than 10 $\mathrm{mm}$ of vertical displacement at the island surface while delivering magma to the 2011-2014 events, we find that the depth of this magma body is more than $25 \mathrm{~km}$. A similar approach to finding the minimum depth of magma bodies was used, for example, by Sigmundsson et al. (1999) for the 1998 eruption at Piton de la Fournaise (La Réunion island).

The inferred overall magma supply rate was probably driven by deeper mantle processes. Periodic pulses of magma occurring approximately every 3 months fed these post-eruptive intrusions. However, no pattern was observed indicating that subsequent intrusions were less energetic (Figure 2); rather, separate high energy pulses were supplied from depth, with each individual pulse decaying with time. The exponentially decay in the magma flow rate may relate to a hydraulic connection between the deep pressure magma source and the intrusions by a magma-filled conduit (e.g., Dvorak \& Okamura, 1987; Dzurisin et al., 2009). Similarly, during the 2014-2015 Bárðarbunga eruption, there was also a continuous connection between the advancing dike intrusion and the overpressure source (Parks et al., 2017; Sigmundsson et al., 2015).

The ascent of magma under the volcanic edifice was probably influenced by the regional and local stress field of the area. In an intraplate region, like the Canary Islands, the regional stress field is expected to be compressive. At El Hierro, the regional maximum horizontal stress axis has been inferred to be oriented NWSE (Geyer et al., 2016). The local stresses depend on the mechanical properties of the crustal layers, and materials of different stiffness and tensile or shear fractures may influence whether an intrusion becomes a sill, an inclined sheet, or a vertical dike and whether it is able to reach the surface (e.g., Gudmundsson, 2011; Rivalta et al., 2015). At El Hierro, the ascent of magma was probably controlled by the magma overpressure resulting from the excess pressure at the reservoir and the buoyancy derived from the density contrast between the magma and the host rock. A magma filled crack opened up a path normal to the minimum compressive stresses. The pulses of magma, gravitationally unstable, ascended to equilibrate the excess pressure, without producing seismicity, until being trapped at $\sim 13-16 \mathrm{~km}$ depth. This depth corresponds to the crust/mantle discontinuity in El Hierro (Martí et al., 2017). When magma finds a layer stiffer than the lower layer where it is intruded, as the crust/mantle boundary, the intrusion may tend to become deflected along the contact, forming a sill (e.g., Gudmundsson, 2011; Kavanagh, 2018; Rivalta et al., 2015). At El Hierro, the crust/mantle boundary may have inhibited magma ascent, favoring accumulation and lateral migration of the magma along the discontinuity.

Magma flow rates of $\sim 300 \mathrm{~m}^{3} / \mathrm{s}$ were not enough to break through the discontinuity and magma spread laterally, producing the measured seismicity and ground deformation. The injection of magma for several days produced enough magma to migrate laterally for some kilometers along the discontinuity forming sills. The lateral movement of the magmatic intrusions away from the island, observed by (i) the evolution of seismicity, (ii) a change in the pattern of horizontal displacements, and (iii) the evolution of the geodetic models, considering their uncertainties, was probably influenced by the compressive regional stresses and the local stresses produced in part by the steep island topography. We also suggest the presence of previous magmatic intrusions, with an effect in the local stresses, influenced the path followed by the magma during each intrusion. Intrusions were distributed over areas that were not affected by previous ones. Magma emplaced 
during previous intrusions probably induced changes in the local stress field, eventually conditioning the magma movement during subsequent intrusions.

The question remains as to why the post-eruptive intrusions did not ascend to the surface as the first magmatic intrusion did during the 2011 pre-eruptive unrest. The total inferred magma volume intruded beneath the island during the 2011 intrusion was estimated at $\sim 40 \times 10^{6} \mathrm{~m}^{3}$ (González et al., 2013; López et al., 2017), similar to the volumes estimated here for the shortest post-eruptive intrusions and lower than the volume inferred for the largest intrusions which occurred in June-July 2012 and March-April 2013 (Figure 9). However, several differences are noted with respect to the posteruptive intrusions. The 2011 pre-eruptive intrusion migrated laterally for almost $15 \mathrm{~km}$, but in a time period of 2 months, instead of 20 days for the largest post-eruptive intrusions. The seismic moment recorded during the pre-eruptive unrest period was lower than during the largest post-eruptive events (Figure 2c). However, the pre-eruptive 2011 intrusion occurred at 10-12 km depth, while the post-eruptive intrusions occurred at 13-16 km depth (Figures 1d and 2a). The 2011 pre-eruptive intrusion was only able to ascend to the surface after the occurrence of an earthquake of magnitude $\mathrm{Mw}$ 4.0, which released enough energy to open a path for the magma to rise to the surface (López et al., 2017). Additional injection of magma 2 weeks before the submarine eruption may have increased the total magma pressure, changing the local stress field as observed by the change in the focal mechanism of the earthquakes and causing the Mw 4.0 earthquake (López et al., 2017). We suggest that the pre-eruptive and eruptive intrusions may have increased the horizontal compressive stresses at El Hierro, influencing the magma migration of the following events and preventing the ascent of magma to shallower zones. Thus, the post-eruptive intrusions formed sills instead of continuing toward the surface. Similarly, during the 1975-1986 Krafla rifting episodes in Iceland, initial dike injections were followed by eruptions when extensional stress had been released and magma could no longer propagate laterally (e.g., Wright et al., 2012).

The post-eruptive intrusions at El Hierro constitute a clear demonstration that magmatic intrusions do not often culminate in an eruption (e.g., Biggs et al., 2014). In contrast to divergent plate boundaries, where crust often forms by injection of vertical dikes (e.g., Wright et al., 2012), at oceanic intraplate islands as El Hierro, the crust is mainly formed by the accumulation of horizontal sill intrusions beneath the volcanoes (e.g., Klügel et al., 2015). These intrusive events, revealed by the observed seismicity and ground deformation, and the magma solidification at depth, may indicate that magmatic underplating at El Hierro contributes to the internal growth of the island. The 2012-2014 magmatic intrusions added $\sim 388 \times 10^{6} \mathrm{~m}^{3}$ of magma in the lower crust, causing the island to uplift $>20 \mathrm{~cm}$.

\section{Conclusions}

The 2011-2014 magmatic activity at El Hierro signifies the emplacement of multiple magmatic intrusions at depth beneath the island. Results of temporal and spatial evolution of geodetic models suggest that the intrusions were installed at $\sim 13-16 \mathrm{~km}$ depth, with initial magma supply rates of $\sim 300 \mathrm{~m}^{3} / \mathrm{s}$ decaying exponentially with time. Magma volumes of $\sim(24-44) \times 10^{6} \mathrm{~m}^{3}$ were intruded beneath the island in less than a week during four short events in September 2012, January 2013, December 2013, and March 2014. The longer June-July 2012 and March-April 2013 intrusions lasted for 20 days. Each of these two events intruded $>120 \times 10^{6} \mathrm{~m}^{3}$ of magma below the volcano. Clear lateral migration of magma was observed away from the center of the island. During the first week, $80 \%$ of the ground deformation and of the total intruded magma volume occurred. The June-July 2012 intrusion is inferred to have formed at a near constant depth, whereas the geodetic models during the March-April 2013 intrusive activity suggest that the intrusion evolved to shallower depths during the first week.

All the intrusions started in the center of the island, suggesting an upflow path from a deep magma reservoir beneath the center of the island. We infer that this mantle magma reservoir become over-pressured, emitting pulses of magma that ascended until being trapped at $\sim 13-16 \mathrm{~km}$. The crust/mantle boundary and previous intrusions may have increased the compressive stress of the area, discouraging the ascent of magma to the surface. Magma flow rates of $\sim 300 \mathrm{~m}^{3} / \mathrm{s}$ were not enough to overcome the barrier for further upward flow. When the magma flow continued for some days, intrusions migrated laterally in the form of sill-like sources. Seismicity and ground deformation were produced as a consequence. 
These events offer an exceptional opportunity to study magmatic sill intrusions emplaced at depth. Since magmatic intrusions may result in an eruption, the knowledge of magma supply, storage, and migration is crucial to forecasting volcanic activity and improving volcano hazard assessment. The 2012-2014 magmatic intrusions at El Hierro added $\sim 388 \times 10^{6} \mathrm{~m}^{3}$ of magma in the lower crust. This magma volume is comparable to the volume of pyroclastic material emitted during the 2011-2012 submarine eruption, displaying the importance of the post-eruptive magmatic intrusions in the overall magmatic episode at El Hierro.

\section{Acknowledgments}

This research has been supported by IGN, the European Community's H2020 Programme grant 731070 (Project EUROVOLC), a grant from Iceland, Liechtenstein, and Norway through the EEA Financial Mechanism, operated by University Complutense de Madrid (NILS Science and Sustainability Programme, 033ABEL-IM-2014B), CGL2014-58821-C21-R MINECO research project, and the European Community's Seventh Framework Programme grant 308377 (Project FUTUREVOLC). RADARSAT2 and COSMO-SkyMed images were provided by the European Space Agency under CAT-1 29252 and 31045 projects, respectively. The data presented in this study can be found in the Supporting Information. In addition, LOS and GNSS deformation data are available from the Zenodo repository (http://doi.org/10.5281/

zenodo.3488697). Relocated earthquakes are available through the referenced article of Domínguez Cerdeña et al. (2018). We wish to thank the IGN group for the deployment and maintenance of the volcano monitoring network on El Hierro island. We are also grateful to Mike Poland, Estelle Chaussard, and an anonymous reviewer for their useful comments that helped us to greatly improve this manuscript.

\section{References}

Anderson, K. R., \& Poland, M. P. (2016). Bayesian estimation of magma supply, storage, and eruption rates using a multiphysical volcano model: Kilauea Volcano, 2000-2012. Earth and Planetary Science Letters, 447, 161-171. https://doi.org/10.1016/j.epsl.2016.04.029

Bagnardi, M., \& Hooper, A. (2018). Inversion of surface deformation data for rapid estimates of source parameters and uncertainties: A Bayesian approach. Geochemistry, Geophysics, Geosystems, 19, 2194-2211. https://doi.org/10.1029/2018GC007585

Becerril, L., Bartolini, S., Sobradelo, R., Marti, J., Morales, J. M., \& Galindo, I. (2014). Long-term volcanic hazard assessment on El Hierro (Canary Islands). Natural Hazards and Earth System Sciences, 14(7), 1853-1870. https://doi.org/10.5194/nhess-14-1853-2014

Bekaert, D. P. S., Walters, R. J., Wright, T. J., Hooper, A. J., \& Parker, D. J. (2015). Statistical comparison of InSAR tropospheric correction techniques. Remote Sensing of Environment, 170, 40-47. https://doi.org/10.1016/j.rse2015.08.035

Benito-Saz, M. A., Parks, M. M., Sigmundsson, F., Hooper, A., \& Garcia-Canada, L. (2017). Repeated magmatic intrusions at El Hierro island following the 2011-2012 submarine eruption. Journal of Volcanology and Geothermal Research, 344, 79-91. https://doi.org/ 10.1016/j.jvolgeores.2017.01.020

Biggs, J., Ebmeier, S. K., Aspinall, W. P., Lu, Z., Pritchard, M. E., Sparks, R. S. J., \& Mather, T. A. (2014). Global link between deformation and volcanic eruption quantified by satellite imagery. Nature Communications, 5. https://doi.org/10.1038/ncomms4471

Carracedo, J. C., Rodríguez Badiola, E., Guillou, H., de la Nuez, J., \& Pérez Torrado, F. J. (2001). Geology and volcanology of La Palma and El Hierro, Western Canaries. Estudios Geológicos, 57(5-6), 175-273.

Chaussard, E., \& Amelung, F. (2012). Precursory inflation of shallow magma reservoirs at west Sunda volcanoes detected by InSAR. Geophysical Research Letters, 39, L21311. https://doi.org/10.1029/2012GL053817

Dañobeitia, J. (1980). Interpretación de la estructura de la corteza en el Archipiélago Canario a partir de perfiles sísmicos profundos de refracción. Ph. D. Thesis,

Díaz-Moreno, A., Ibanez, J. M., De Angelis, S., Garcia-Yeguas, A., Prudencio, J., Morales, J., et al. (2015). Seismic hydraulic fracture migration originated by successive deep magma pulses: The 2011-2013 seismic series associated to the volcanic activity of El Hierro Island. Journal of Geophysical Research: Solid Earth, 120, 7749-7770. https://doi.org/10.1002/2015JB012249

Domínguez Cerdeña, I., del Fresno, C., \& Moreno, A. G. (2014). Seismicity patterns prior to the 2011 El Hierro eruption. Bulletin of the Seismological Society of America, 104(1), 567-575. https://doi.org/10.1785/0120130200

Domínguez Cerdeña, I., García-Cañada, L., Benito-Saz, M. A., del Fresno, C., Lamolda, H., Pereda de Pablo, J., \& Sánchez Sanz, C. (2018). On the relation between ground surface deformation and seismicity during the 2012-2014 successive magmatic intrusions at El Hierro island. Tectonophysics, 744, 422-437. https://doi.org/10.1016/j.tecto.2018.07.019

Dvorak, J. J., \& Okamura, A. T. (1987). A hydraulic model to explain variations in summit tilt rate at Kilauea and Mauna Loa volcanoes. $U$. S. Geological Survey Professional Papers, 1350(2), 1281-1296.

Dzurisin, D., Lisowski, M., \& Wicks, C. W. (2009). Continuing inflation at Three Sisters volcanic center, central Oregon Cascade Range, USA from GPS, leveling, and InSAR observations. Bulletin of Volcanology, 71(10), 1091-1110. https://doi.org/10.1007/s00445-009-0296-4

Ebinger, C., Ayele, A., Keir, D., Rowland, J., Yirgu, G., Wright, T., et al. (2010). Length and timescales of rift faulting and magma intrusion: The afar rifting cycle from 2005 to present. Annual Review of Earth and Planetary Sciences, 38(38), 439-466. https://doi.org/10.1146/ annurev-earth-040809-152333

Fialko, Y., Khazan, Y., \& Simons, M. (2001). Deformation due to a pressurized horizontal circular crack in an elastic half-space, with applications to volcano geodesy. Geophysical Journal International, 146(1), 181-190. https://doi.org/10.1046/j.1365-246X.2001.00452.x

Geyer, A., Marti, J., \& Villasenor, A. (2016). First-order estimate of the Canary Islands plate-scale stress field: Implications for volcanic hazard assessment. Tectonophysics, 679, 125-139. https://doi.org/10.1016/j.tecto.2016.04.010

González, P. J., Samsonov, S. V., Pepe, S., Tiampo, K. F., Tizzani, P., Casu, F., et al. (2013). Magma storage and migration associated with the 2011-2012 El Hierro eruption: Implications for crustal magmatic systems at oceanic island volcanoes. Journal of Geophysical Research: Solid Earth, 118, 4361-4377. https://doi.org/10.1002/jgrb.50289

Gudmundsson, A. (2011). Deflection of dykes into sills at discontinuities and magma-chamber formation. Tectonophysics, 500(1-4), 50-64. https://doi.org/10.1016/j.tecto.2009.10.015

Hooft, E. E. E., Heath, B. A., Toomey, D. R., Paulatto, M., Papazachos, C. B., Nomikou, P., et al. (2019). Seismic imaging of Santorini: Subsurface constraints on caldera collapse and present-day magma recharge. Earth and Planetary Science Letters, 514, 48-61. https://doi. org/10.1016/j.epsl.2019.02.033

Hooper, A., Bekaert, D., Spaans, K., \& Arikan, M. (2012). Recent advances in SAR interferometry time series analysis for measuring crustal deformation. Tectonophysics, 514, 1-13. https://doi.org/10.1016/j.tecto.2011.10.013

Hooper, A., Ofeigsson, B., Sigmundsson, F., Lund, B., Einarsson, P., Geirsson, H., \& Sturkell, E. (2011). Increased capture of magma in the crust promoted by ice-cap retreat in Iceland. Nature Geoscience, 4(11), 783-786. https://doi.org/10.1038/ngeo1269

Kavanagh, J. L., Burns, A. J., Hazim, S. H., Wood, E. P., Martin, S. A., Hignett, S., \& Dennis, D. J. C.(2018). Challenging dyke ascent models using novel laboratory experiments: Implications for reinterpreting evidence of magma ascent and volcanism. Journal of Volcanology and Geothermal Research, 354, 87-101). https://doi.org/10.1016/j.jvolgeores.2018.01.002

Klügel, A., Longpré, M. A., García-Cañada, L., \& Stix, J. (2015). Deep intrusions, lateral magma transport and related uplift at ocean island volcanoes. Earth and Planetary Science Letters, 431, 140-149. https://doi.org/10.1016/j.epsl.2015.09.031

Lamolda, H., Felpeto, A., \& Bethencourt, A. (2017). Time lag between deformation and seismicity along monogenetic volcanic unrest periods: The case of El Hierro island (Canary Islands). Geophysical Research Letters, 44, 6771-6777. https://doi.org/10.1002/ 2017GL074494 
Lin, Y., Simons, M., Hetland, E. A., Muse, P., \& DiCaprio, C. (2010). A multiscale approach to estimating topographically correlated propagation delays in radar interferograms. Geochemistry, Geophysics, Geosystems, 11, Q09002. https://doi.org/10.1029/2010GC003228

López, C., Benito-Saz, M. A., Martí, J., del-Fresno, C., García-Canada, L., Albert, H., \& Lamolda, H. (2017). Driving magma to the surface: The 2011-2012 El Hierro volcanic eruption. Geochemistry, Geophysics, Geosystems, 18, 3165-3184. https://doi.org/10.1002/ 2017GC007023

Martí, J., Villasenor, A., Geyer, A., Lopez, C., \& Tryggvason, A. (2017). Stress barriers controlling lateral migration of magma revealed by seismic tomography. Scientific Reports, 7(1), 1-10. https://doi.org/10.1038/srep40757

McTigue, D. F. (1987). Elastic stress and deformation near a finite spherical magma body-Resolution of the point-source paradox. Journal of Geophysical Research, 92(B12), 12931-12940. https://doi.org/10.1029/JB092iB12p12931

Mogi, K. (1958). Relations between the eruptions of various volcanoes and the deformations of the ground surfaces around them. Bulletin Earthquake Research Institute, University of Tokyo, 36, 99-134.

Ofeigsson, B. G., Hooper, A., Sigmundsson, F., Sturkell, E., \& Grapenthin, R. (2011). Deep magma storage at Hekla volcano, Iceland, revealed by InSAR time series analysis. Journal of Geophysical Research, 116, B05401. https://doi.org/10.1029/2010JB007576

Okada, Y. (1992). Internal deformation due to shear and tensile faults in a half-space. Bulletin of the Seismological Society of America, 82(2), $1018-1040$.

Parks, M. M., Heimisson, E. R., Sigmundsson, F., Hooper, A., Vogfjord, K. S., Arnadottir, T., et al. (2017). Evolution of deformation and stress changes during the caldera collapse and dyking at Bardarbunga, 2014-2015: Implication for triggering of seismicity at nearby Tungnafellsjokull volcano. Earth and Planetary Science Letters, 462, 212-223. https://doi.org/10.1016/j.epsl.2017.01.020

Parks, M. M., Moore, J. D. P., Papanikolaou, X., Biggs, J., Mather, T. A., Pyle, D. M., et al. (2015). From quiescence to unrest: 20 years of satellite geodetic measurements at Santorini volcano, Greece. Journal of Geophysical Research: Solid Earth, 120, 1309-1328. https://doi. org/10.1002/2014JB011540

Pedersen, R., \& Sigmundsson, F. (2006). Temporal development of the 1999 intrusive episode in the Eyjafjallajokull volcano, Iceland, derived from InSAR images. Bulletin of Volcanology, 68(4), 377-393. https://doi.org/10.1007/s00445-005-0020-y

Pritchard, M. E., \& Simons, M. (2004). An InSAR-based survey of volcanic deformation in the central Andes. Geochemistry, Geophysics, Geosystems, 5, Q02002. https://doi.org/10.1029/2003GC000610

Rivalta, E., Taisne, B., Bunger, A. P., \& Katz, R. F. (2015). A review of mechanical models of dike propagation: Schools of thought, results and future directions. Tectonophysics, 638, 1-42. https://doi.org/10.1016/j.tecto.2014.10.003

Sainz-Maza, S., Montesinos, F. G., Martí, J., Arnoso, J., Calvo, M., \& Borreguero, A. (2017). Structural interpretation of El Hierro (Canary Islands) rifts system from gravity inversion modelling. Tectonophysics, 712, 72-81. https://doi.org/10.1016/j.tecto.2017.05.010

Sanchez-Pastor, P., Obermann, A., \& Schimmel, M. (2018). Detecting and locating precursory signals during the 2011 El Hierro, Canary Islands, submarine eruption. Geophysical Research Letters, 45, 10288-10297. https://doi.org/10.1029/2018GL079550

Segall, P. (2013). Volcano deformation and eruption forecasting. Geological Society, London, Special Publications, 380(1), 85-106.

Sigmundsson, F., Durand, P., \& Massonnet, D. (1999). Opening of an eruptive fissure and seaward displacement at Piton de la Fournaise volcano measured by RADARSAT satellite radar interferometry. Geophysical Research Letters, 26(5), 533-536. https://doi.org/10.1029/ 1999GL900055

Sigmundsson, F., Hooper, A., Hreinsdottir, S., Vogfjord, K. S., Ofeigsson, B. G., Heimisson, E. R., et al. (2015). Segmented lateral dyke growth in a rifting event at Bardarbunga volcanic system, Iceland. Nature, 517(7533), 191-195. https://doi.org/10.1038/nature14111

Sigmundsson, F., Hreinsdottir, S., Hooper, A., Arnadottir, T., Pedersen, R., Roberts, M. J., et al. (2010). Intrusion triggering of the 2010 Eyjafjallajokull explosive eruption. Nature, 468(7322), 426-430. https://doi.org/10.1038/nature09558

Somoza, L., Gonzalez, F. J., Barker, S. J., Madureira, P., Medialdea, T., de Ignacio, C., et al. (2017). Evolution of submarine eruptive activity during the 2011-2012 El Hierro event as documented by hydroacoustic images and remotely operated vehicle observations. Geochemistry, Geophysics, Geosystems, 18, 3109-3137. https://doi.org/10.1002/2016GC006733

Toda, S., Stein, R. S., \& Sagiya, T. (2002). Evidence from the AD 2000 Izu islands earthquake swarm that stressing rate governs seismicity. Nature, 419(6902), 58-61. https://doi.org/10.1038/nature00997

Villasante-Marcos, V., \& Pavón-Carrasco, F. J. (2014). Palaeomagnetic constraints on the age of Lomo Negro volcanic eruption (El Hierro, Canary Islands). Geophysical Journal International, 199(3), 1497-1514. https://doi.org/10.1093/gji/ggu346

Watts, A. B. (1994). Crustal structure, gravity-anomalies and flexure of the lithosphere in the vicinity of the Canary-Islands. Geophysical Journal International, 119(2), 648-666. https://doi.org/10.1111/j.1365-246X.1994.tb00147.x

Wauthier, C., Roman, D. C., \& Poland, M. P. (2016). Joint analysis of geodetic and earthquake fault-plane solution data to constrain magmatic sources: A case study from Kilauea volcano. Earth and Planetary Science Letters, 455, 38-48. https://doi.org/10.1016/j. epsl.2016.09.011

Williams, C. A., \& Wadge, G. (1998). The effects of topography on magma chamber deformation models: Application to Mt Etna and radar interferometry. Geophysical Research Letters, 25(10), 1549-1552. https://doi.org/10.1029/98GL01136

Wright, T. J., Sigmundsson, F., Pagli, C., Belachew, M., Hamling, I. J., Brandsdottir, B., et al. (2012). Geophysical constraints on the dynamics of spreading centres from rifting episodes on land. Nature Geoscience, 5(4), 242-250. https://doi.org/10.1038/ngeo1428 